\title{
McClear: a new model estimating downwelling solar radiation at ground level in clear-sky conditions
}

\author{
M. Lefèvre ${ }^{1}$, A. Oumbe ${ }^{1,2}$, P. Blanc ${ }^{1}$, B. Espinar ${ }^{1}$, B. Gschwind ${ }^{1}$, Z. Qu ${ }^{1}$, L. Wald ${ }^{1}$, M. Schroedter-Homscheidt ${ }^{2}$, \\ C. Hoyer-Klick ${ }^{2}$, A. Arola ${ }^{3}$, A. Benedetti ${ }^{4}$, J. W. Kaiser ${ }^{4,5,6}$, and J.-J. Morcrette ${ }^{4}$ \\ ${ }^{1}$ MINES ParisTech, CS10207, 06904 Sophia Antipolis, France \\ ${ }^{2}$ German Aerospace Center (DLR), Wessling, Germany \\ ${ }^{3}$ Finnish Meteorological Institute, Kuopio, Finland \\ ${ }^{4}$ ECMWF, Reading, UK \\ ${ }^{5}$ King's College London, London, UK \\ ${ }^{6}$ Max Planck Institute for Chemistry, Mainz, Germany
}

Correspondence to: L. Wald (lucien.wald@mines-paristech.fr)

Received: 30 January 2013 - Published in Atmos. Meas. Tech. Discuss.: 10 April 2013

Revised: 24 July 2013 - Accepted: 9 August 2013 - Published: 17 September 2013

\begin{abstract}
A new fast clear-sky model called McClear was developed to estimate the downwelling shortwave direct and global irradiances received at ground level under clear skies. It is a fully physical model replacing empirical relations or simpler models used before. It exploits the recent results on aerosol properties, and total column content in water vapour and ozone produced by the MACC project (Monitoring Atmosphere Composition and Climate). It accurately reproduces the irradiance computed by the libRadtran reference radiative transfer model with a computational speed approximately $10^{5}$ times greater by adopting the abaci, or look-up table, approach combined with interpolation functions. It is therefore suited for geostationary satellite retrievals or numerical weather prediction schemes with many pixels or grid points, respectively. McClear irradiances were compared to 1 min measurements made in clear-sky conditions at several stations within the Baseline Surface Radiation Network in various climates. The bias for global irradiance comprises between -6 and $25 \mathrm{~W} \mathrm{~m}^{-2}$. The RMSE ranges from $20 \mathrm{~W} \mathrm{~m}^{-2}$ ( $3 \%$ of the mean observed irradiance) to $36 \mathrm{~W} \mathrm{~m}^{-2}(5 \%)$ and the correlation coefficient ranges between 0.95 and 0.99 . The bias for the direct irradiance comprises between -48 and $+33 \mathrm{~W} \mathrm{~m}^{-2}$. The root mean square error (RMSE) ranges from $33 \mathrm{~W} \mathrm{~m}^{-2}(5 \%)$ to $64 \mathrm{~W} \mathrm{~m}^{-2}(10 \%)$. The correlation coefficient ranges between 0.84 and 0.98 . This work demonstrates the quality of the McClear model combined with MACC products, and indirectly the quality of the aerosol properties modelled by the MACC reanalysis.
\end{abstract}

\section{Introduction}

The downwelling solar irradiance observed at ground level on horizontal surfaces and integrated over the whole spectrum (total irradiance) is called surface solar irradiance (SSI). It is the sum of the direct irradiance, from the direction of the sun, and the diffuse, from the rest of the sky vault, and is also called the global irradiance. The SSI is an essential climate variable (ECV) as established by the Global Climate Observing System in August 2010 (GCOS, 2012). Knowledge of the SSI and its geographical distribution is of prime importance for numerous domains where SSI plays a major role as e.g. weather, climate, biomass, and energy.

Accurate assessments of SSI can be retrieved from satellite data, and several studies demonstrate the superiority of satellite data over interpolation methods applied to sparse measurements performed within a radiometric network (Perez et al., 1997; Zelenka et al., 1999). Given the scarcity of long-term SSI measurements made at ground level, several authors mention that satellite-derived SSI may supplement these measurements (Ba et al., 2001; Blanc et al., 2010; Cano et al., 1986; Darnell et al., 1996; Diabaté et al., 1988; Elias and Roujean, 2008; Lefèvre et al., 2007; Posselt et al., 2012; Raschke et al., 1987; Schiffer and Rossow, 1985; Schmetz, 1989).

Hereafter, a model estimating the SSI under clear sky is called a clear-sky model. As it describes the SSI in a cloudfree atmosphere, it estimates a realistic upper limit of the 
SSI (Gueymard, 2012; Long and Ackerman, 2000). In many methods for the assessment of the SSI, all-sky irradiance is derived from the modelled clear-sky SSI by the attenuation or a modification factor due to clouds (Cano et al., 1986; Posselt et al., 2012; Raschke et al., 1987; Rigollier et al., 2004). While the all-sky SSI changes mainly with clouds, the SSI under clear sky is strongly dependent on the composition of the atmosphere, namely the variable parameters aerosol and water vapour. Aerosols play a major role due to the diversity in scattering and absorbing properties according to their type, and the spatial and temporal heterogeneity of their number, size, chemical composition, and shape (Deepshikha et al., 2006; Deneke et al., 2008; Elias and Roujean, 2008; Gueymard, 2005; Xu et al., 2011).

The MACC project (Monitoring Atmosphere Composition and Climate), funded by the European Commission, is preparing the operational provision of global aerosol property forecasts together with physically consistent total column content in water vapour and ozone (Kaiser et al., 2012a; Peuch et al., 2009). Up to now a multi-annual reanalysis data set is provided and used here (Inness et al., 2013). Such information has not been available so far from any operational numerical weather prediction (NWP) centre.

A new clear-sky model called McClear has been developed to exploit this new input data source for estimating the downwelling shortwave direct and global irradiances received at ground level. The aim of this article is to describe this model (Sect. 2) and its implementation (Sect. 3), and to establish its performance (Sects. 4 to 6) with respect to high-quality measurements of SSI and the existing literature (Sect. 7).

\section{The McClear model}

Let $E^{\text {diff }}$ denote the diffuse irradiance on the horizontal plane, $E^{\text {dir }}$ the direct (or beam) irradiance on the horizontal plane, and $E^{\text {glo }}$ the global irradiance:

$E^{\mathrm{glo}}=E^{\mathrm{diff}}+E^{\mathrm{dir}}$.

If $E_{0}$ denotes the irradiance that is received on a horizontal surface at the top of the atmosphere for the location and time under consideration, the clearness index KT is defined as

$\mathrm{KT}=E^{\mathrm{glo}} / E_{0}$.

The clearness index is also called global transmissivity of the atmosphere, or atmospheric transmitance, or atmospheric transmission. In the same way, we define the direct clearness index $\mathrm{KT}^{\mathrm{dir}}$ as

$\mathrm{KT}^{\mathrm{dir}}=E^{\mathrm{dir}} / E_{0}$.

The model McClear aims at producing both $E^{\mathrm{glo}}$ and $E^{\mathrm{dir}}$. The first constraint put in its development is that it should sufficiently accurately reproduce the SSI estimated by accurate radiative transfer models (RTM). The RTM libRadtran (Mayer and Kylling, 2005; Mayer et al., 2010) is taken here as a reference. The deviations between McClear and libRadtran outputs must obey constraints similar to those for radiation measurements (WMO, 2008): the bias shall be less than $3 \mathrm{~W} \mathrm{~m}^{-2}$, and $95 \%$ of the differences should be less than $20 \mathrm{~W} \mathrm{~m}^{-2}$.

The major constraint is that it should deliver time series of irradiance much faster than libRadtran. The computational speed should be approximately $10^{5}$ times greater in order to enable routine production in real-time forecasting systems.

One solution to obey these constraints is to adopt the abaci approach combined with interpolation functions. The use of abaci - also known as look-up tables (LUT) - is not new in this domain (Deneke et al., 2008; Huang et al., 2011; Mueller et al., 2009; Schulz et al., 2009). It reveals an efficient and fast means to provide estimates of values otherwise available from complex and slow models. One drawback is the resources and time needed to compute the abaci that may amount to months. Another drawback is that the abaci formulation has to be adapted to the available input data source. Therefore, this paper deals with the specifics of an abaci approach for typical numerical weather prediction output characteristics as represented in the MACC reanalysis data set.

A set of abaci and interpolation functions to speed up the solution of the radiative transfer equations is designed, developed and implemented. This ensemble of abaci and interpolation functions as well as functions to exploit them for aggregation in time and computation of the sun position is the model McClear.

Inputs to McClear are the solar zenith angle, the ground albedo and 6 parameters describing the optical state of the atmosphere:

- total column content of ozone and water vapour,

- vertical profile of temperature, pressure, density, and volume mixing ratio for gases as a function of altitude taken in the AFGL data sets (see Sect. 3.2),

- aerosol optical depth (AOD) at $550 \mathrm{~nm}$, Ångström coefficient, and aerosol type: urban, continental clean, continental polluted, continental average, maritime clean, maritime polluted, maritime tropical, Antarctic, and desert (see Sect. 3.4),

and other parameters describing the geographical location and the time:

- latitude, longitude and elevation above mean sea level (a.s.l.) of the site of interest,

- period of time requested,

- integration period, also known as the summarization period, of the radiation: $1 \mathrm{~min}, 15 \mathrm{~min}, 1 \mathrm{~h}$, and 1 day, 
- and time sampling step, usually identical to the integration period.

Aerosols are described by standard aerosol types instead of using modelled AOD at different wavelengths explicitly. At the first glance this can be criticized as making no use of available additional aerosol type information and it creates the need of a transition matrix from MACC output to aerosol type (see Sect. 3.4). However, it enhances the flexibility of the McClear use for other future sources of input data using other internal aerosol models and/or other output wavelengths. Additionally, it avoids the increase of the abaci dimensions in order to cover all AOD wavelengths and the shift for spectral interpolation assumptions from the AOD level on the irradiance level afterwards in the broadband irradiance generation.

The abaci contain

- the clearness index KT for ground albedo equal to 0 , 0.1, and 0.9 (see Sect. 3.1),

- the direct clearness index $\mathrm{KT}^{\mathrm{dir}}$ for null ground albedo,

for selected values of the 10 following parameters:

- solar zenith angle $\Theta_{S}$,

- ground albedo,

- the altitude of the ground level and elevation above the ground,

- and the 6 parameters describing the optical state of the clear atmosphere and already listed above.

These values are called node points. The clearness indices are obtained by running libRadtran for these node points. Interpolation functions permit to interpolate between node points.

Altitude of the ground level and elevation above the ground are both needed because the 6 clear-sky parameters are computed in the MACC analysis for a very smooth terrain and therefore represent the atmospheric properties for this atmospheric column. The altitude of this smooth terrain model may differ from the elevation of the more local site of interest and the SSI should be corrected, assuming that the difference in SSI between the local elevation and the smooth terrain is equivalent to the difference in SSI between a similar elevation above ground level, i.e. in the atmosphere, and the smooth terrain. The correction is explained in Sect. 3.3.

An optimization was made for the selection of the node points and interpolation functions with the following constraints: (i) minimize the number of node points in order to have abaci as small as possible, (ii) select/design interpolation/extrapolation functions as fast as possible, and (iii) interpolated values must be close to the libRadran results with already mentioned constraints. The last constraints on the difference with libRadtran were checked for each input separately as well as the combination of all inputs using all node points and interpolation functions.
The optimization was done for each of the 10 inputs listed above. A Monte Carlo technique is applied to randomly generate sets of inputs to libRadtran within the 10-D space, with the exception of the current parameter which is regularly sampled with a small step. The optical properties were selected by considering their observed marginal distribution. More precisely, the uniform distribution is chosen as a model for marginal probability for all parameters except aerosol optical thickness, Ångström coefficient, and total column ozone. The chi-square law for aerosol optical thickness, the normal law for the Ångström coefficient, and the beta law for total column ozone have been selected. The parameters of the laws are empirically determined from the analyses of the observations made in the AERONET network for aerosol properties and from meteorological satellite-based ozone products.

For all inputs, the selected interpolation/extrapolation functions are linear interpolators/extrapolators, except for the solar zenith angle $\Theta_{\mathrm{S}}$. For the latter, the modified BeerLambert (MLB) function proposed by Mueller et al. (2009) has been studied. To obey the constraints, a 5-piecewise MLB was retained with the following angles: $0^{\circ}, 60^{\circ}, 75^{\circ}$, $80^{\circ}, 85^{\circ}$, and $89.9^{\circ}$ instead of the originally proposed two angles 0 and $60^{\circ}$. Shortly after the design of the abaci was frozen, Qu et al. (2011) demonstrated that a 4-piecewise MLB with the angles $0^{\circ}, 60^{\circ}, 75^{\circ}, 85^{\circ}$, and $89.9^{\circ}$ would have been applicable as well.

Following Oumbe et al. (2011), the efficiency and accuracy of piecewise linear functions to estimate changes in $E^{\text {glo }}$ and $E^{\mathrm{dir}}$ with altitude above the ground is sufficient.

The formula of Vermote et al. (1994, 1997),

$\operatorname{KT}\left(\rho_{\mathrm{g}}\right)=\mathrm{KT}\left(\rho_{\mathrm{g}}=0\right) /\left(1-\rho_{\mathrm{g}} S\right)$,

describes the change in KT as a function of the ground albedo $\rho_{\mathrm{g}}$ and the atmospheric spherical albedo $S . \rho_{g}$ is an input while $S$ is unknown. In principle, $S$ can be computed knowing KT for any value of $\rho_{\mathrm{g}}$ using Eq. (4). In practice, better results are attained if $S$ is computed for two values of $\rho_{\mathrm{g}}$ -0.1 , and 0.9 using Eq. (4) - and then is linearly interpolated/extrapolated for the actual $\rho_{g}$ :

$$
\begin{aligned}
& a=\left[S\left(\rho_{\mathrm{g}}=0.9\right)-S\left(\rho_{\mathrm{g}}=0.1\right)\right] / 0.8 \\
& b=S\left(\rho_{\mathrm{g}}=0.1\right)-0.1 a \\
& S=a \rho_{\mathrm{g}}+b .
\end{aligned}
$$

In total, this design results in 1674 abaci. One abacus corresponds to a given atmospheric profile and a given type of aerosol. In an abacus, the list of node points is as follows:

- total column content in ozone (in Dobson unit): 200, $300,400,500$,

- total column content in water vapour $\left(\mathrm{kg} \mathrm{m}^{-2}\right): 0.1,3$, $5,7,10,15,20,30,40,60,80$, and 100 , 
- aerosol optical depth at $550 \mathrm{~nm}: 0.01,0.05,0.1,0.2,0.3$, $0.5,1,1.5,2$, and 5 ,

- aerosol Ångström coefficient: $-1,-0.5,0,0.5,1,1.5$, 2,3 , and 4 ,

- site elevation above mean sea level (km): 0, 1, 2, 3, 4, 5, 6 , and 7 ,

- elevation above ground level $(\mathrm{km}): 0,0.5,1,1.5$, and 2,

- solar zenith angle (deg): 0, 60, 75, 80, 85, and 89.9.

\section{Practical implementation of McClear}

McClear can be run with self-defined inputs. More interestingly, it is capable of ingesting atmospheric data from the MACC modelling and from the MODIS (Moderate Resolution Imaging Spectroradiometer) estimates for ground albedo. This section details the practical implementation of McClear.

\subsection{Ground albedo}

The MCD43C1 and MCD43C2 data, derived from MODIS images, are 16-day composites provided as a level-3 product projected to a $0.05^{\circ}$ grid in latitude/longitude. They are produced every 8 days with 16 days of acquisition, where the given date is that of the first day of the 16-day period. These data sets contain three model parameters, called fiso, fvol, and fgeo (Schaaf et al., 2002). fiso describes the isotropic part of the bidirectional reflectance distribution function (BRDF); the two other parameters are linked to the viewing and illuminating geometry to describe the anisotropic part of the BRDF. The directional hemispherical reflectance (DHR) also known as black-sky albedo - and the bihemispherical reflectance (BHR) - also known as white-sky albedo - (e.g. Schaepman-Strub et al., 2006) are computed from the BRDF using formulas in Schaaf et al. (2002). Defining $K^{\mathrm{dir}}\left(\rho_{\mathrm{g}}\right)$ as

$K^{\operatorname{dir}}\left(\rho_{\mathrm{g}}\right)=E^{\mathrm{dir}} / E^{\mathrm{glo}}\left(\rho_{\mathrm{g}}\right)$

where $E^{\text {dir }}$ does not depend on $\rho_{\mathrm{g}}$, the ground albedo $\rho_{\mathrm{g}}$ is given by

$\rho_{\mathrm{g}}=\mathrm{BHR}+K^{\mathrm{dir}}\left(\rho_{\mathrm{g}}\right)(\mathrm{DHR}-\mathrm{BHR})$.

The major difficulty in Eq. (7) is that $\rho_{\mathrm{g}}$ depends upon $K^{\mathrm{dir}}$, which depends itself on $\rho_{\mathrm{g}}$. By combining Eqs. (4)-(7), and denoting $\Delta=($ DHR - BHR $)$, one obtains a second-order equation in KT which is the quantity of interest:

$$
\begin{aligned}
a \Delta^{2} \mathrm{KT}^{\mathrm{dir}^{2}} & +\mathrm{KT}\left[\mathrm{KT}\left(\rho_{\mathrm{g}}=0\right)+(2 a \mathrm{BHR}+b) \Delta \mathrm{KT}^{\mathrm{dir}}\right] \\
& +\left(a \mathrm{BHR}^{2}+b \mathrm{BHR}-1\right) \mathrm{KT}^{2}=0 .
\end{aligned}
$$

Using the Monte Carlo technique to randomly select 100000 samples, it is found that Eq. (8) has only one solution that respects $\mathrm{KT}>\mathrm{KT}^{\mathrm{dir}}$. Therefore, Eq. (8) is used to compute KT and Eq. (7) provides $\rho_{\mathrm{g}}$.

In a practical manner, once a request is made for a given site, the three BRDF parameters fiso, fvol, and fgeo are taken from the closest MCD43C1 or MCD43C2 grid point. Then, Eq. (8) is solved for KT for each minute of the day.

The difference between the MCD43C1 and MCD43C2 products is that $\mathrm{MCD} 43 \mathrm{C} 2$ is a snow-free version of MCD43C1. Both products exhibit gaps in time and space. Two approaches have been tested to palliate the lack of data.

In the first approach, the three BRDF parameters were taken from the MCD43C2 product for the previous, current and following months for the current day. They were interpolated in time for each minute of the day, taking into account the possible absence of data. Sometimes, data may not be available for three months in a row. In these cases, the parameters were replaced by their mean values computed for the given month over the period 2004-2011. Over the ocean, fiso was set to 0.02 (Wald and Monget, 1983) and the two parameters to 0 . Several gaps in space and time were still observed. Presence of snow is not accounted for, and this may induce errors in the diffuse irradiance in some cases.

The second approach consisted in computing mean values of the three BRDF parameters from the MCD43C1 product for each of the twelve months of the year over the period 2004-2011. Each mean value was allotted to the mid-day of each month. The values for the current day were computed by linear interpolation using the current month and that before or after depending on the case. A great deal of effort has been made on the completion of data which are missing mostly in water-covered areas. The "Land Cover Type" product is also a MODIS product using the same grid as MCD43C1. It allows the identification of pixels containing water and the proportion of water in this pixel. Let $W$ denote the binary mask for water; $W=1$ if the pixel has been classified as "water" at least once for the given month during the period 20012009 covered by the "Land Cover Type" product, and is 0 otherwise. Let $P$ be the average proportion of the water. The typical triplet $f_{W}=$ (fiso, fvol, fgeo) for water areas was defined by the mode of the valid triplets (fiso, fvol, fgeo) for water pixels comprised between latitude $-45^{\circ}$ and latitude $45^{\circ}$. $f_{\mathrm{W}}$ was allotted to each unknown water pixel for which $P=1$. Then, if a water pixel exhibited a valid triplet $f$ and a proportion of water $P$ less than $1, f$ was replaced by a linear combination $P f_{\mathrm{W}}+(1-P) f$. A moving average of \pm 1 month was applied followed by a median filter of $11 \times 11$ pixels to fill gaps. This two-step filtering was repeated but with a window of \pm 2 months. Then, a median filter of $21 \times 21$ pixels was applied. Still unknown were a few pixels in the middle of the ocean, extreme southern part of the Antarctic Ocean, and Greenland. They were treated manually and were allotted the mean value of the triplets $f$ averaged in their neighbourhood.

When compared to ground-based measurements of the SSI as discussed later, both approaches gave the same results with very small differences not taking into account the gaps. The 
second approach is used in the following. It has the advantage that it makes easier the implementation of McClear.

\subsection{Atmospheric profile}

The five vertical profiles of temperature, pressure, density, and volume mixing ratio for gases as a function of altitude used in McClear are those from the USA Air Force Geophysics Laboratory (AFGL) as implemented in libRadtran: tropics, mid-latitude summer and winter, and sub-Arctic summer and winter. A mask has been constructed for the automatic selection of the atmospheric profile for any site. The Koeppen climate classification map (FAO, 1997) has been manually modified for North America, China and Africa following Trewartha (1954). Other maps of climate classification could have been suitable and possibly more accurate. But aiming at partitioning the world into five classes only, a very limited level of detail is sufficient. The sub-Arctic profiles are allotted to climate zones noted EF, ET, Dc, Dd in Trewartha (1954), the tropical profile to Aw, As, Af, and Am, and the mid-latitude profiles are allotted to the rest. Oceans are not covered by these climate maps; extension was manually made. As for the seasons, November to April is considered as boreal winter (austral summer).

\subsection{Altitude correction}

The 6 inputs from MACC are given for grid nodes, which are separated by approximately $100 \mathrm{~km}$. A very smooth elevation model is used in MACC analyses, and each node has a known local mean elevation above mean sea level (a.s.l.). The MACC-equivalent elevation for the local site under consideration is computed by linear interpolation of the MACC elevations of the 4 neighbouring grid nodes. Then, interpolation in the clearness index is made for this MACC-equivalent elevation using the two closest nodes "site elevation" in the abaci. If the actual elevation of the local site is less than the MACCequivalent elevation, the clearness index is set to that corresponding to the MACC-equivalent elevation. Otherwise, an additional linear interpolation/extrapolation is performed using the nodes "elevation above ground level".

\subsection{Aerosols properties}

Inputs to McClear are the aerosol optical depth at $550 \mathrm{~nm}$, Ångström coefficient, and aerosol type. The MACC reanalysis delivers total aerosol optical depth at 550 and $1240 \mathrm{~nm}$, from which the Ångström coefficient is derived. It delivers also partial optical depths at $550 \mathrm{~nm}$ for dust, organic, sea salt, sulphate, and black carbon aerosol species (Benedetti et al., 2009; Kaiser et al., 2012b; Morcrette et al., 2008, 2009).

These partial optical depths are used to automatically determine the aerosol type, and more exactly the mixture whose name describes the typical origin of the particle ensembles: urban, continental clean, continental polluted, continental average, maritime clean, maritime polluted, maritime tropical,
Antarctic, and desert. Table 1 in Holzer-Popp et al. (2002) gives percentage contributions to the total optical depth of the respective mixtures by the basic components: water soluble, water insoluble, sea salt accumulation mode, coarse mode, soot, and mineral transported. It is used as a guide for converting MACC species into types. The partial optical depths are converted to fractions of the total optical depth, in percent. The conversion algorithm is described in Fig. 1. The type "Antarctic" is solely defined by the latitude.

The algorithm has been tested by running it over several years of MACC data. Several sites were selected for which one or more types were expected to dominate, such as sites in the Indian and South Pacific oceans (maritime tropical and maritime clean and polluted), North Atlantic Ocean (maritime, continental, and urban), Australian and Sahelian deserts (desert and continental), Tibetan Plateau and Amazonian forest (mostly continental and maritime), Zaire forest (continental and urban), and large conurbations: Calcutta and New Delhi (urban and continental polluted), Beijing (urban), Shanghai and Mexico (urban, continental, and maritime), Tamanrasset, Sede Boqer, and Mezaira (desert).

For each site, the histogram of the resulting types has been drawn and checked that it was close to our expectations. Though satisfactory as a whole, more work is needed on this algorithm, which may fail sometimes. Figure 2 exhibits $E^{\text {glo }}$ measured at the station Carpentras every $1 \mathrm{~min}$ on 10 June 2006 and that estimated by McClear as an example of such a failure. This day was clear, except in the early morning before 07:00 UTC. One can see that both curves agree perfectly; the aerosol type was found as "urban". There is an exception to the agreement from 08:00 to 11:30 UTC where the type was found as "maritime polluted". This leads to an overestimation of $E^{\text {glo }}$ with a peak of $30 \mathrm{~W} \mathrm{~m}^{-2}$, from $998 \mathrm{~W} \mathrm{~m}^{-2}$ down to $968 \mathrm{~W} \mathrm{~m}^{-2}$, i.e. $3 \%$ of $E^{\text {glo }}$ at 11:30 UTC. At this instant, $E^{\text {dir }}$ amounts to $910 \mathrm{~W} \mathrm{~m}^{-2}$ and is unchanged as it does not depend upon the aerosol type.

\subsection{Computing instantaneous clear-sky SSI for any site}

Aerosol properties, and total column contents of water vapour and ozone in MACC are given every $3 \mathrm{~h}$, starting at 00:00 UT. A bi-linear interpolation in space is applied to compute a time series of $3 \mathrm{~h}$ values for the given location. A further interpolation in time is performed yielding time series of these atmospheric quantities every $1 \mathrm{~min}$ in order to enable the production of 1 and $15 \mathrm{~min}$ SSI.

These 1 min values are inputs to the McClear model. The solar zenith angle is computed with the SG2 algorithm (Blanc and Wald, 2012) for the middle of the minute. An abacus is selected for the given atmospheric profile and aerosol type. A series of interpolations as described above is performed to yield the clearness indices. The ordering of interpolation of parameters was found as having a negligible influence on the results. For the sake of computing speed, 


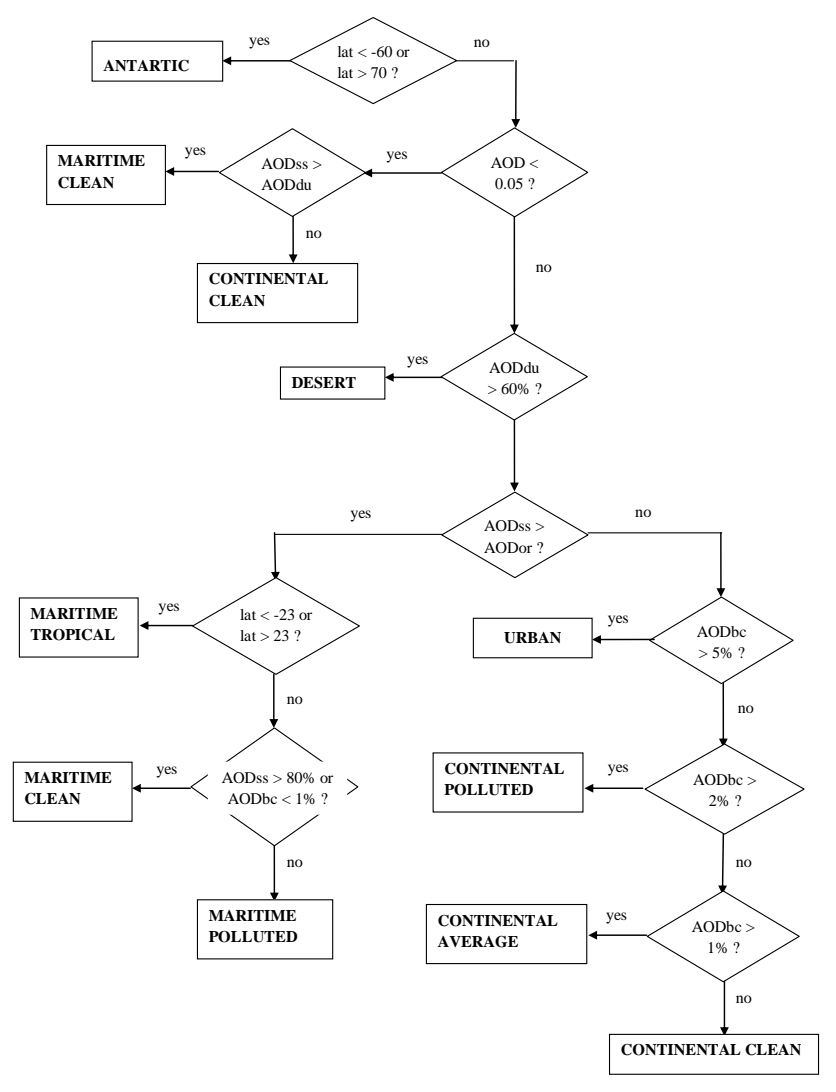

Fig. 1. Sketch of the algorithm converting the total optical depth (AOD) and partial optical depths of MACC species - dust (AODdu), sea salt (AODss), black carbon (AODbc), and organic matter (AODor) - into aerosol types: urban, continental clean, continental polluted, continental average, maritime clean, maritime polluted, maritime tropical, Antarctic, and desert. "lat" is latitude.

linear interpolations are performed first, then the MLB interpolator, and finally the computation of the ground albedo.

The resulting clearness indices are assumed to be constant over $1 \mathrm{~min}$. The $1 \mathrm{~min}$ mean irradiance is computed by Eqs. (2)-(3), where the solar geometry parameters and $E_{0}$ are determined by SG2 for the beginning and end of the minute. If requested, the $1 \mathrm{~min}$ irradiances are summarized to yield $15 \mathrm{~min}$, hourly and daily values in Universal Time or True Solar Time.

Various tests have been made for comparing outputs from McClear and libRadtran to check that both models yield similar results. Several tests have been made with a random selection of inputs and were satisfactory. The targets were met: the bias was less than $3 \mathrm{~W} \mathrm{~m}^{-2}$ and $95 \%$ of the differences were less than $20 \mathrm{~W} \mathrm{~m}^{-2}$.

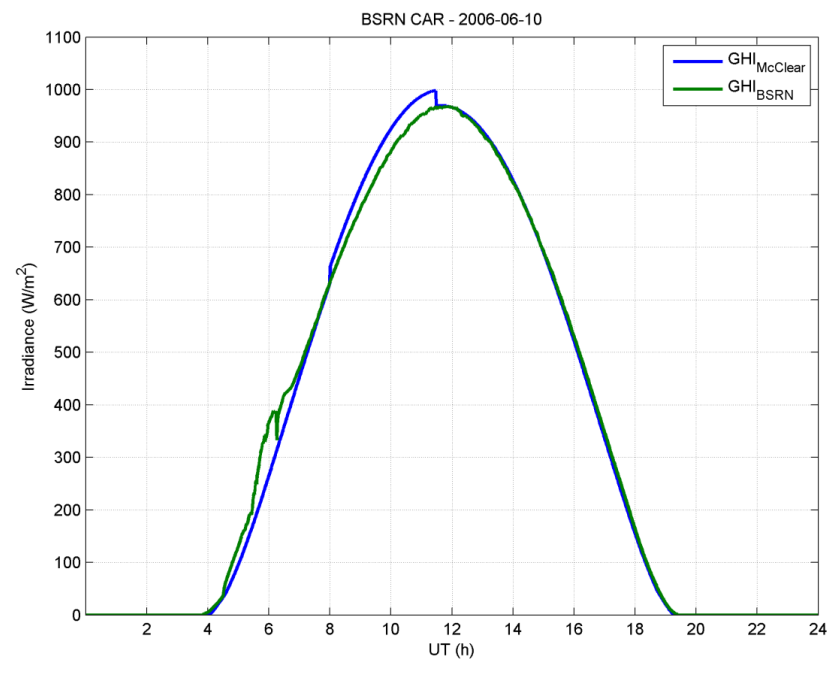

Fig. 2. Profiles of the $1 \mathrm{~min}$ global irradiance measured (BSRN) and estimated on 10 June 2006 at Carpentras in the southeast of France as an example of a rare failure case of the aerosol type selection scheme. GHI: global horizontal irradiance.

\section{BSRN data for validation}

The Baseline Surface Radiation Network (BSRN) is a collection of measurements of $E^{\text {glo }}, E^{\text {diff }}$ and beam normal irradiance (BNI) of high quality suitable for validation. Measurements are acquired every $1 \mathrm{~min}$. Uncertainty requirements for BSRN data are $5 \mathrm{~W} \mathrm{~m}^{-2}$ for global irradiance and $2 \mathrm{~W} \mathrm{~m}^{-2}$ for direct irradiance (Ohmura et al., 1998). Data sets were collected for 11 stations representing a variety of climates (Table 1) for the period 2005-2008, except for Palaiseau, Xianghe and Lauder (2005-2007) and Brasilia (2006-2007).

Following the recommendations of Roesch et al. (2011), only the BSRN measurements were kept which obey the following constraints:

if $\Theta_{S} \leq 75^{\circ}, 1.08 \geq\left(E^{\text {diff }}+E^{\text {dir }}\right) / E^{\text {glo }} \geq 0.92$

if $\Theta_{\mathrm{S}}>75^{\circ}, 1.15 \geq\left(E^{\mathrm{diff}}+E^{\mathrm{dir}}\right) / E^{\mathrm{glo}} \geq 0.85$.

Roesch et al. (2011) note a percentage of missing data of $4 \%$ for global irradiance and $13 \%$ for direct irradiance for all studied BSRN data.

Two filters have been applied on the remaining BSRN data in order to retain reliable clear-sky instants. The first one was a constraint on the amount of diffuse irradiance with respect to the global irradiance since the direct irradiance is prominent in the case of clear sky. Only those minutes for which $E^{\text {diff }} / E^{\text {glo }}<0.3$, i.e. when the diffuse component is much less than the direct one, have been retained.

The second filter dealt with the temporal variability of the irradiance. If there is no cloud, the sky should be clear for a long period. Checking this would avoid cases of broken clouds or noticeable spatial heterogeneity around the site if ergodicity is assumed. The first step of this filter was to retain 
Table 1. List of BSRN stations used for validation.

\begin{tabular}{lllrrrr}
\hline Station & Code & Country & Latitude & Longitude & $\begin{array}{r}\text { Elevation } \\
\text { a.s.1. (m) }\end{array}$ & $\begin{array}{r}\text { MACC mean } \\
\text { altitude (m) }\end{array}$ \\
\hline Barrow & BAR & USA (Alaska) & 71.323 & -156.607 & 8 & 31 \\
Palaiseau & PAL & France & 48.713 & 2.208 & 156 & 126 \\
Carpentras & CAR & France & 44.083 & 5.059 & 100 & 538 \\
Payerne & PAY & Switzerland & 46.815 & 6.944 & 491 & 943 \\
Xianghe & XIA & China & 39.754 & 116.962 & 32 & 326 \\
Tateno & TAT & Japan & 36.050 & 140.133 & 25 & 246 \\
Sede Boqer & SBO & Israel & 30.905 & 34.782 & 500 & 450 \\
Tamanrasset & TAM & Algeria & 22.780 & 5.510 & 1385 & 1012 \\
Brasilia & BRB & Brazil & -15.601 & -47.713 & 1023 & 808 \\
Alice Springs & ASP & Australia & -23.798 & 133.888 & 547 & 554 \\
Lauder & LAU & New Zealand & -45.045 & +169.689 & 350 & 509 \\
\hline
\end{tabular}

only periods with enough measurements that have passed the first filter. A given instant $t$, expressed in min, was kept only if at least $30 \%$ of the 1 min observations in both intervals $[t-90, t]$ and $[t, t+90]$ have been retained after the first filter. A corrected clearness index, $\mathrm{KT}^{\prime}$ (Ineichen and Perez, 1999) is computed for this instant:

$\mathrm{KT}^{\prime}=\mathrm{KT} /[1.031 \exp (-1.4 /(0.9+9.4 / m))+0.1]$,

where $m$ is the air mass defined by Kasten and Young (1989):

$m\left(\Theta_{\mathrm{S}}\right)=\left(p / p_{0}\right) /\left[\cos \left(\Theta_{\mathrm{S}}\right)+0.50572\left(\Theta_{\mathrm{S}}+6.07995\right)^{-1.6364}\right]$,

where $\Theta_{\mathrm{S}}$ is expressed in degree, and $p$ and $p_{0}$ are respectively the pressure at the site under consideration and that at sea level.

An instant was considered clear if the standard deviation of $\mathrm{KT}^{\prime}$ in the interval $[t-90, t+90]$ was less than a threshold, set empirically to 0.02 . Only these 1 min clear-sky instants were retained for the validation. Figure 3 displays a time series of $E^{\text {glo }}$ for the selected clear-sky instants in the year 2005 in Payerne, in black circles. Payerne experiences a large number of clear skies during the year and many instants are selected. In this graph are also drawn the clear-sky instants selected by the algorithm of Long and Ackerman (2000), in light-grey crosses. One may see that they are differences between the results. The proposed algorithm presents less low values of $E^{\text {glo }}$ than that of Long and Ackerman and offers more confidence in the fact that the instant is clear.

\section{Validation using BSRN data}

The validation of McClear was made by comparing the aforementioned 1 min BSRN values for clear sky and the McClear values calculated for these instants and the location of the site. Following the ISO standard (1995), the deviations were computed by subtracting measurements for each instant from the McClear estimations, and they were summarized by the

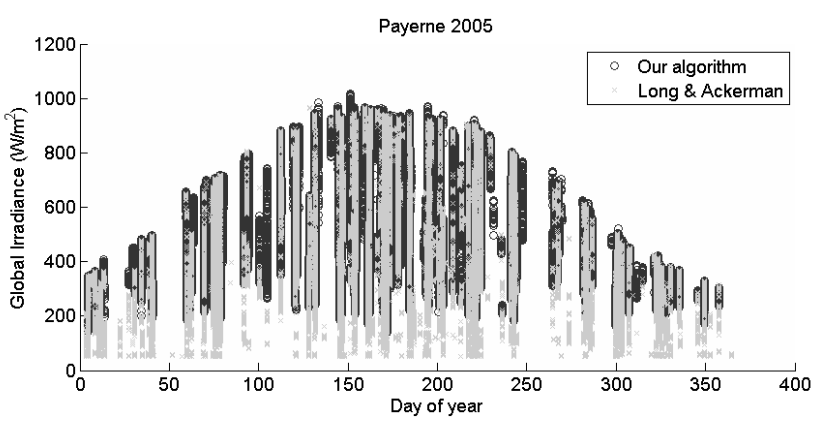

Fig. 3. Time series of Eglo for the selected clear-sky instants in the year 2005 in Payerne, in black circles. Clear-sky instants selected by the algorithm of Long and Ackerman (2000) are in light-grey crosses.

bias, the root mean square error (RMSE), and the squared correlation coefficient. The parameters of the least-squares fitting line were also computed. Relative values are expressed with respect to the mean observed value. This operation has been performed for $E^{\text {glo }}$ and $E^{\text {dir }}, \mathrm{KT}$ and $\mathrm{KT}^{\text {dir }}$, site per site, with all instants merged, and for different classes of $E^{\mathrm{glo}}$, $E^{\text {dir }}, \mathrm{KT}, \mathrm{KT}^{\mathrm{dir}}, \Theta_{\mathrm{S}}$, aerosol optical depth at $550 \mathrm{~nm}$, aerosol Ångström coefficient, aerosol type, atmospheric profile, total content in water vapour and ozone, ground albedo, year and month.

Figures 4 and 5 are scatter density plots between measured and estimated $E^{\text {glo }}$ and $E^{\text {dir }}$ for Payerne. An overall good fit is observed between estimates and observations: the points are well aligned along the $1: 1$ line with a small tendency towards overestimation with high $E^{\text {glo }}$ and a limited scattering. The squared correlation coefficients are very large: 0.99 and 0.96 respectively, meaning that $99 \%$ and $96 \%$ of information contained in $E^{\text {glo }}$ and $E^{\text {dir }}$ is well explained by McClear. The relative bias is small $-4 \%$ for $E^{\text {glo }}$ and $1 \%$ for $E^{\mathrm{dir}}-$ as is the RMSE: $5 \%$ and $7 \%$. As expected, performances in $E^{\mathrm{dir}}$ are less than for $E^{\mathrm{glo}}$; the effects of aerosols are more pronounced in beam than in global SSI. Cases of 


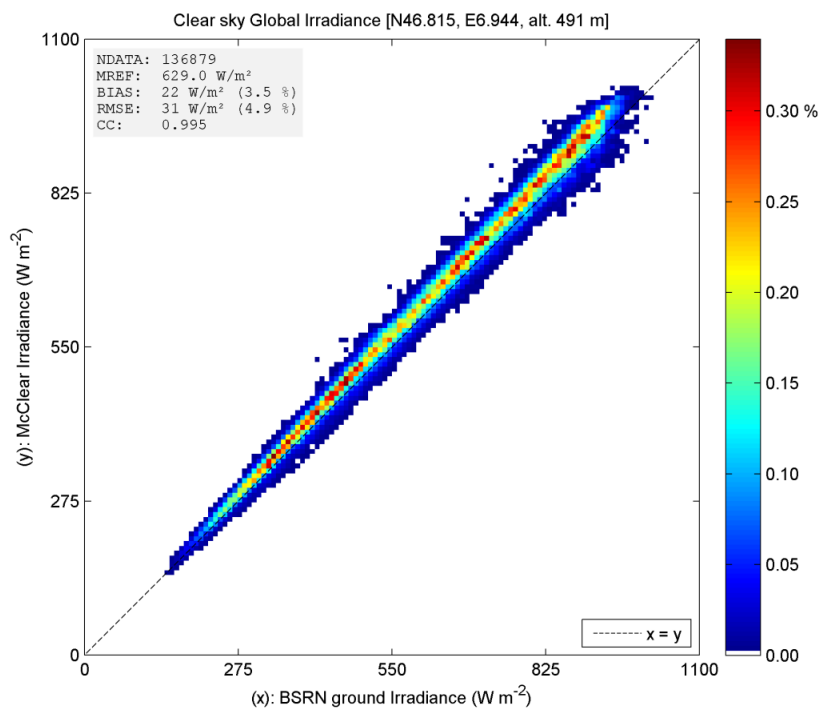

Fig. 4. Scatter density plot between BSRN 1 min clear-sky data and McClear. Payerne. Global irradiance on horizontal surface.

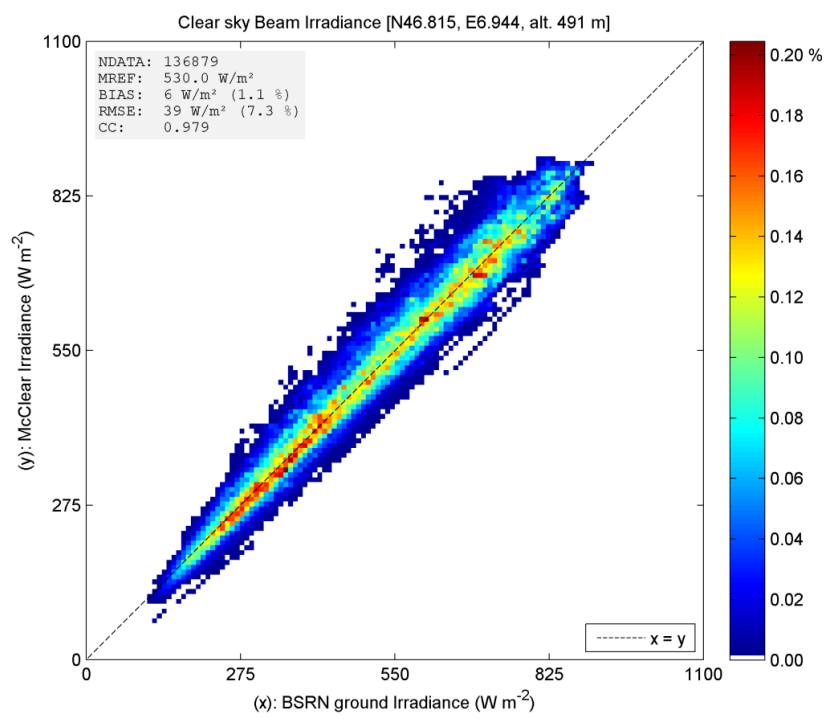

Fig. 5. Scatter density plot between BSRN 1 min clear-sky data and McClear. Payerne. Beam irradiance on horizontal surface.

large deviations can be related to errors in estimation of the aerosol optical thickness. As a whole, there is a slight overestimation by McClear for both $E^{\text {glo }}$ and $E^{\text {dir }}$. The bias and RMSE exhibit a tendency to decrease with increasing $\Theta_{S}$. This will be discussed later. Aerosol types are mostly "maritime polluted" by far, then "urban", then "continental polluted"; the aerosol optical depth at $550 \mathrm{~nm}$ is mostly found between 0.01 and 0.30 . No trend is observed in bias and RMSE as a function of these properties.

Figures 6 and 7 are scatter density plots between BSRN data and McClear estimates for the global and beam clearness indices. The changes in solar radiation at the top of the

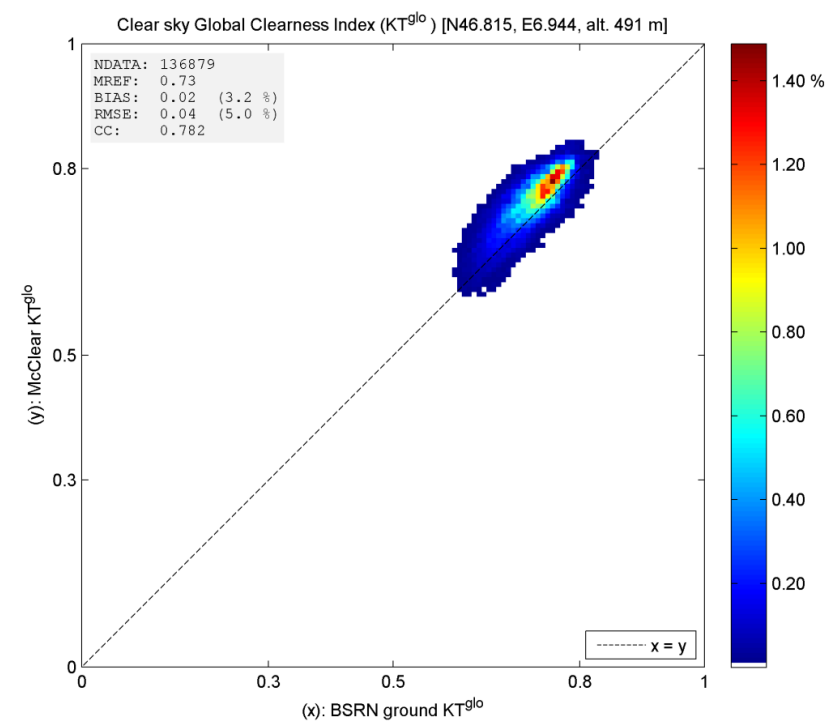

Fig. 6. Scatter density plot between BSRN 1 min clear-sky data and McClear. Payerne. Global clearness index KT.

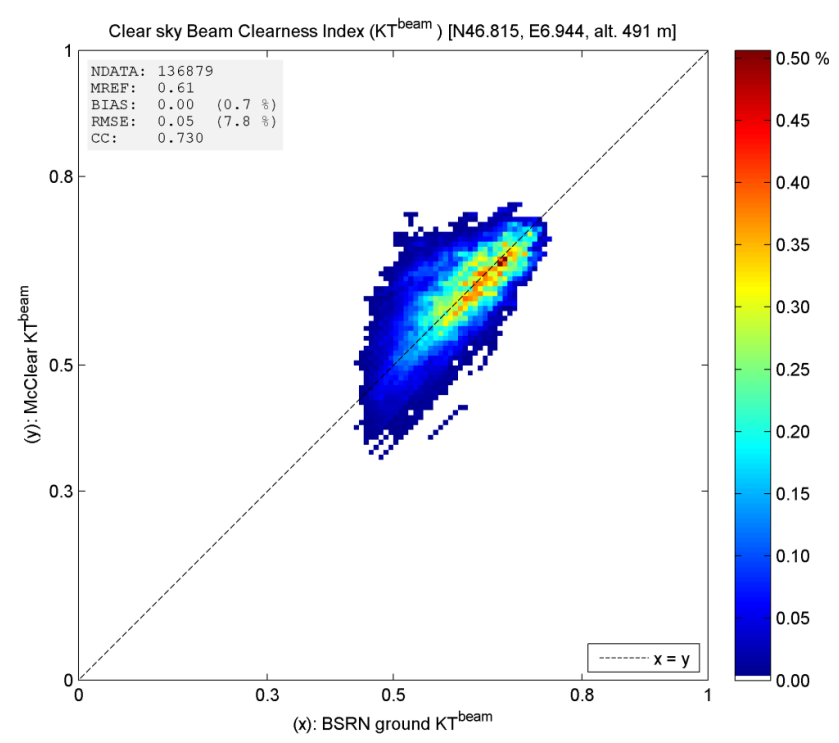

Fig. 7. Scatter density plot between BSRN 1 min clear-sky data and McClear. Payerne. Beam clearness index KTdir.

atmosphere due to changes in geometry, namely the daily course of the sun and seasonal effects, are usually well reproduced by models and lead to a de facto correlation between observations and estimates of SSI hiding potential weaknesses. Clearness indices KT and $\mathrm{KT}^{\mathrm{dir}}$ are stricter indicators of the performances of a model regarding its ability to estimate the optical state of the atmosphere. Though KT and $\mathrm{KT}^{\mathrm{dir}}$ are not completely independent of $\Theta_{\mathrm{S}}$ as they decrease as $\Theta_{\mathrm{S}}$ increases, the dependency is much less pronounced than in SSI. In Figs. 6 and 7, KT and KT ${ }^{\text {dir }}$ exhibit a lower squared correlation coefficient than $E^{\mathrm{glo}}$ and $E^{\mathrm{dir}}: 0.69$ and 


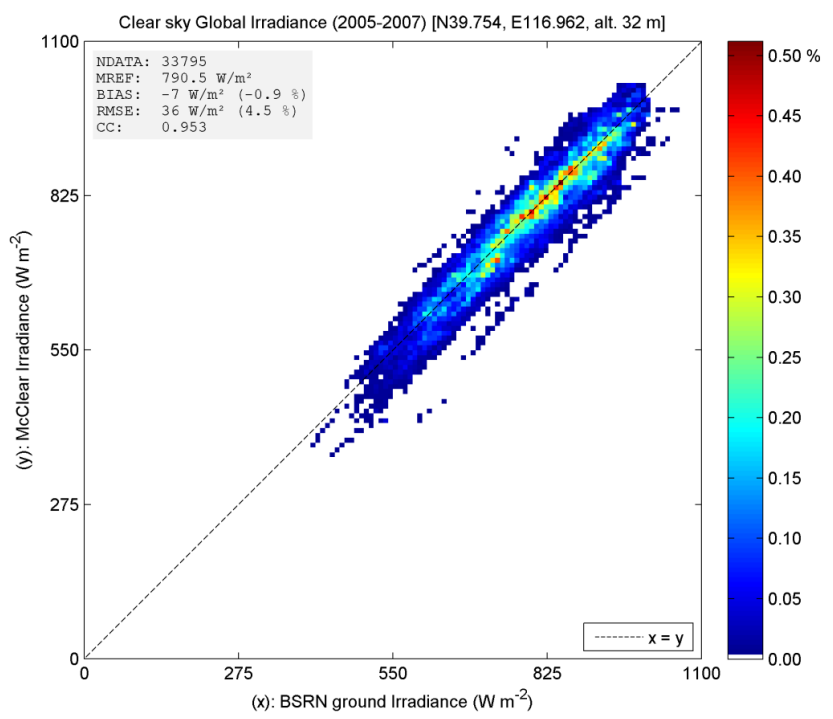

Fig. 8. Scatter density plot between BSRN 1 min clear-sky data and McClear. Xianghe. Global irradiance on horizontal surface.

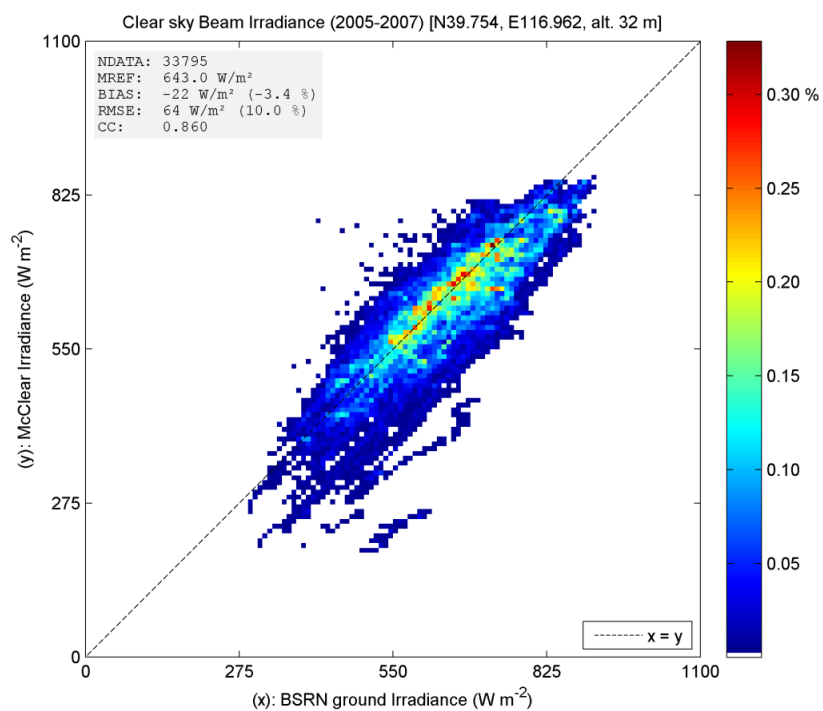

Fig. 9. Scatter density plot between BSRN 1 min clear-sky data and McClear. Xianghe. Beam irradiance on horizontal surface.

0.53 , instead of 0.99 and 0.96 . These low correlation coefficients are explained by the limited range of values taken by these indices because only clear sky is dealt with and do not necessarily imply poor performance. In both figures, the set of points is well aligned along the $1: 1$ line with a slight overestimation for $\mathrm{KT}$ and no bias for $\mathrm{KT}^{\mathrm{dir}}$. The relative bias and RMSE for KT are $3 \%$ and $5 \%$, similar to those for ${ }^{\text {glo }}$. The relative bias and RMSE for $\mathrm{KT}^{\mathrm{dir}}$ are small: $1 \%$ and $8 \%$, very similar to those for $E^{\text {dir }}$.

Figures 8 to 11 are scatter density plots between BSRN data and McClear estimates for respectively $E^{\mathrm{glo}}, E^{\mathrm{dir}}, \mathrm{KT}$, and $\mathrm{KT}^{\mathrm{dir}}$ for Xianghe. Xianghe is a rural city but under the

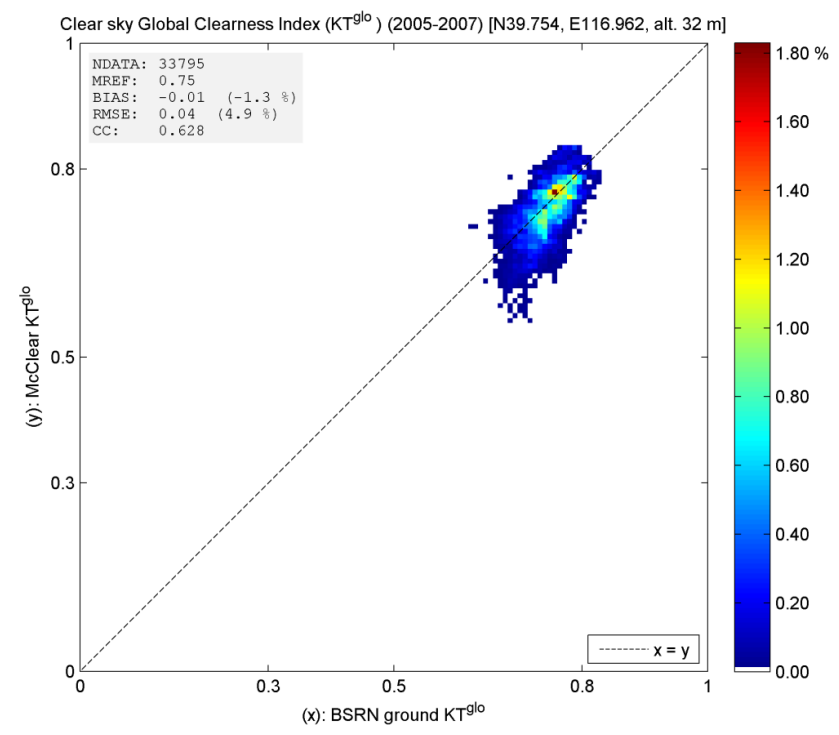

Fig. 10. Scatter density plot between BSRN 1 min clear-sky data and McClear. Xianghe. Global clearness index KT.

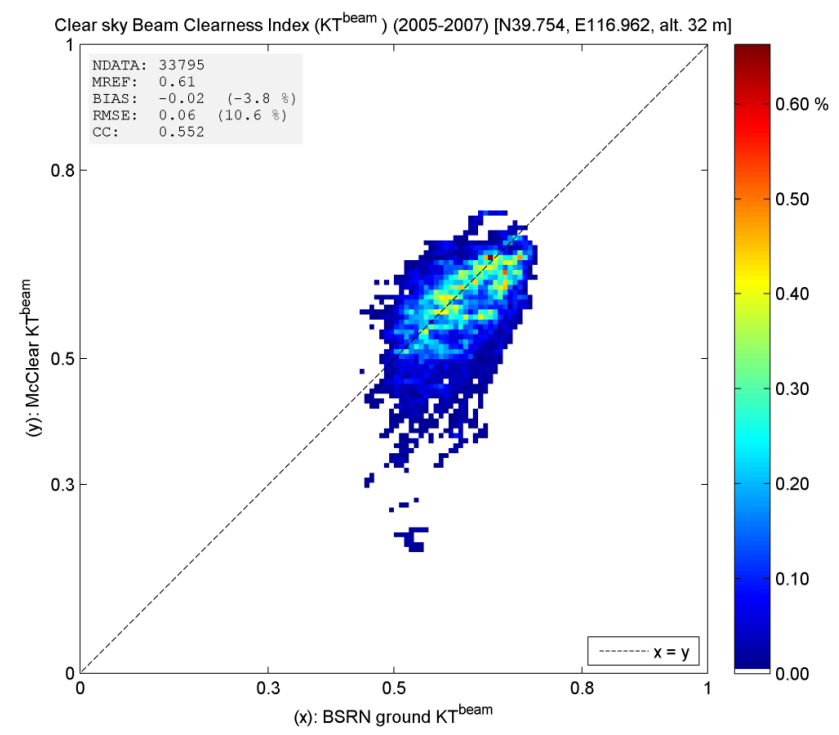

Fig. 11. Scatter density plot between BSRN 1 min clear-sky data and McClear. Xianghe. Beam clearness index KTdir.

influence of the air pollution in Beijing (Wang et al., 2011). It is also the seat of an AERONET station, which shows that the fine mode is very often encountered. An overall good fit is observed between estimates and observations for both $E^{\text {glo }}$ and $E^{\mathrm{dir}}$. The relative bias is small $--1 \%$ for $E^{\mathrm{glo}}$ and $-3 \%$ for $E^{\mathrm{dir}}-$ as is the RMSE: $5 \%$ and $10 \%$. The squared correlation coefficients are large for the global (0.91) but low for the direct $(0.74)$, meaning that $91 \%$ and $74 \%$ of information contained in $E^{\text {glo }}$ and $E^{\text {dir }}$ is well explained by McClear. Aerosol types estimated by McClear are mostly "urban" by far, then "desert" and then "continental polluted" in 
Table 2. Comparison between clear-sky global irradiances measured by BSRN and estimated by McClear.

\begin{tabular}{llrrrrrrr}
\hline Station & $\begin{array}{l}\text { Number of } \\
\text { samples }\end{array}$ & $\begin{array}{r}\text { Mean } \\
\text { observed } \\
\text { value } \mathrm{W} \mathrm{m}^{-2}\end{array}$ & $\begin{array}{r}\text { Bias } \\
\mathrm{W} \mathrm{m}^{-2}\end{array}$ & $\begin{array}{r}\text { Rel. } \\
\text { bias } \\
\%\end{array}$ & $\begin{array}{r}\text { RMSE } \\
\mathrm{W} \mathrm{m}^{-2}\end{array}$ & $\begin{array}{r}\text { Fitted } \\
\text { RME } \\
\text { straight } \\
\text { line }\end{array}$ & $\begin{array}{r}\text { Squared } \\
\text { correl. } \\
\text { coeff. }\end{array}$ \\
\hline Barrow & 70283 & 498 & -6 & $-1 \%$ & 21 & $4 \%$ & $0.96 x+14$ & 0.98 \\
Palaiseau & 29222 & 598 & 7 & $1 \%$ & 25 & $4 \%$ & $1.03 x-8$ & 0.99 \\
Carpentras & 300468 & 596 & +20 & $+3 \%$ & 29 & $5 \%$ & $1.04 x-1$ & 0.99 \\
Payerne & 136879 & 629 & +22 & $+4 \%$ & 31 & $5 \%$ & $1.02 x+10$ & 0.99 \\
Xianghe & 33795 & 791 & -7 & $-1 \%$ & 36 & $5 \%$ & $0.98 x+8$ & 0.91 \\
Tateno & 133433 & 590 & +10 & $+2 \%$ & 29 & $5 \%$ & $1.01 x+3$ & 0.98 \\
Sede Boqer & 304550 & 785 & +12 & $+2 \%$ & 27 & $4 \%$ & $0.96 x+40$ & 0.99 \\
Tamanrasset & 331045 & 791 & +8 & $+1 \%$ & 20 & $3 \%$ & $0.96 x+38$ & 0.99 \\
Brasilia & 73563 & 649 & +25 & $+4 \%$ & 35 & $5 \%$ & $1.02 x+13$ & 0.99 \\
Alice Springs & 442315 & 715 & +11 & $+2 \%$ & 23 & $3 \%$ & $1.00 x+12$ & 0.99 \\
Lauder & 117090 & 600 & +6 & $+1 \%$ & 21 & $4 \%$ & $0.99 x+13$ & 0.99 \\
\hline
\end{tabular}

Table 3. Comparison between clear-sky beam irradiances on horizontal surface measured by BSRN and estimated by McClear.

\begin{tabular}{|c|c|c|c|c|c|c|c|c|}
\hline Station & $\begin{array}{l}\text { Number of } \\
\text { samples }\end{array}$ & $\begin{array}{r}\text { Mean } \\
\text { observed } \\
\text { value } \mathrm{W} \mathrm{m}^{-2}\end{array}$ & $\begin{array}{r}\text { Bias } \\
\mathrm{W} \mathrm{m}^{-2}\end{array}$ & $\begin{array}{r}\text { Rel. } \\
\text { bias } \\
\%\end{array}$ & $\begin{array}{l}\text { RMSE } \\
\mathrm{W} \mathrm{m}^{-2}\end{array}$ & $\begin{array}{r}\text { Rel. } \\
\text { RMSE } \\
\%\end{array}$ & $\begin{array}{l}\text { Fitted } \\
\text { straight } \\
\text { line }\end{array}$ & $\begin{array}{r}\text { Squared } \\
\text { orcrel. } \\
\text { coeff. }\end{array}$ \\
\hline Barrow & 70283 & 406 & -21 & $-5 \%$ & 41 & $10 \%$ & $0.96 x-3$ & 0.93 \\
\hline Palaiseau & 29222 & 492 & -3 & $-1 \%$ & 37 & $7 \%$ & $1.02 x-13$ & 0.96 \\
\hline Carpentras & 300468 & 505 & -1 & $-0 \%$ & 35 & $7 \%$ & $1.00 x-2$ & 0.97 \\
\hline Payerne & 136879 & 530 & +6 & $+1 \%$ & 39 & $7 \%$ & $0.99 x+14$ & 0.96 \\
\hline Xianghe & 33795 & 642 & -22 & $-4 \%$ & 64 & $11 \%$ & $0.86 x+66$ & 0.74 \\
\hline Tateno & 133433 & 485 & -16 & $-3 \%$ & 44 & $9 \%$ & $1.04 x-37$ & 0.94 \\
\hline Sede Boqer & 304550 & 667 & -48 & $-7 \%$ & 62 & $9 \%$ & $0.98 x-38$ & 0.95 \\
\hline Tamanrasset & 331045 & 653 & +16 & $+2 \%$ & 48 & $7 \%$ & $1.05 x-14$ & 0.95 \\
\hline Brasilia & 73563 & 560 & +33 & $+6 \%$ & 48 & $9 \%$ & $1.06 x+1$ & 0.98 \\
\hline Alice Springs & 442315 & 634 & +4 & $+1 \%$ & 33 & $5 \%$ & $1.02 x-10$ & 0.98 \\
\hline Lauder & 117090 & 544 & -32 & $-6 \%$ & 48 & $9 \%$ & $0.93 x+3$ & 0.98 \\
\hline
\end{tabular}

agreement with AERONET observations. Wang et al. (2011) found that the aerosol optical depth estimated by MODIS and further assimilated in the MACC analyses is greater than that observed by the AERONET instrument. This may explain the underestimation of $E^{\text {dir }}$ by McClear. The range of values for $\mathrm{KT}$ and $\mathrm{KT}^{\text {dir }}$ are very limited (Figs. 10 and 11). As a consequence, the correlation coefficients are low. The bias is small $--1 \%$ for $\mathrm{KT}$ and $-4 \%$ for $\mathrm{KT}^{\mathrm{dir}}-$ as is the RMSE: $5 \%$ and $11 \%$.

Tables 2 and 3 report statistical quantities on the deviations between estimates and measurements in $E^{\text {glo }}$ and $E^{\text {dir }}$ for the 11 stations. Similar tables were constructed for KT and $\mathrm{KT}^{\mathrm{dir}}$ (Tables 4 and 5).

The correlation coefficient in $E^{\text {glo }}$ is very large $(r \geq 0.95)$ for all stations (Table 2). The bias ranges between -7 and $+25 \mathrm{~W} \mathrm{~m}^{-2}$, i.e. less than $4 \%$ of the mean observed value. Largest biases in relative value are found in Brasilia (Brazil), Payerne (Switzerland), and Carpentras (France). The slope of the fitting line is close to 1 , between 0.96 and 1.04 . The
RMSE ranges between 20 and $36 \mathrm{~W} \mathrm{~m}^{-2}$ and is less than $5 \%$ of the mean observed value in all cases.

One should note that the statistical quantities slightly vary from one year to another. For example, the bias in $E^{\text {glo }}$ for Payerne is $23 \mathrm{~W} \mathrm{~m}^{-2}$ in $2005,17 \mathrm{~W} \mathrm{~m}^{-2}$ in $2006,23 \mathrm{~W} \mathrm{~m}^{-2}$ in 2007 , and $26 \mathrm{~W} \mathrm{~m}^{-2}$ in 2008. As a whole, no clear trend was observed between these quantities and the year. There is also no clear trend with the aerosol properties and type, ground albedo, or content in ozone and water vapour. However, it appears that results are usually better for the summer months than for winter. The bias varies with $\Theta_{\mathrm{S}}$ though no trend appears (Fig. 12). The RMSE exhibits a tendency to decrease with increasing $\Theta_{S}$, but one should note that the changes may be complex (Fig. 13). The relative bias and the relative RMSE are not constant as a function of $\Theta_{\mathrm{S}}$.

The correlation coefficient for $E^{\text {dir }}$ (Table 3 ) is also very large $(r \geq 0.96)$ for all stations except Xianghe $(r=$ $0.86)$. The bias ranges between -48 and $+33 \mathrm{~W} \mathrm{~m}^{-2}$, and is less than $7 \%$ of the mean observed value. Lowest biases in absolute values, less than $6 \mathrm{~W} \mathrm{~m}^{-2}$, are found in 
Table 4. Comparison between clear-sky global clearness indices measured by BSRN and estimated by McClear.

\begin{tabular}{llrrrrrr}
\hline Station & $\begin{array}{l}\text { Number of } \\
\text { samples }\end{array}$ & $\begin{array}{r}\text { Mean } \\
\text { observed } \\
\text { value }\end{array}$ & Bias & $\begin{array}{r}\text { Rel. } \\
\text { bias } \\
\%\end{array}$ & RMSE & $\begin{array}{r}\text { Rel. } \\
\text { RMSE } \\
\%\end{array}$ & $\begin{array}{r}\text { Squared } \\
\text { correl. } \\
\text { coeff. }\end{array}$ \\
\hline Barrow & 70283 & 0.76 & -0.017 & $-2 \%$ & 0.033 & $4 \%$ & 0.77 \\
Palaiseau & 29222 & 0.71 & +0.002 & $+0 \%$ & 0.029 & $4 \%$ & 0.62 \\
Carpentras & 300468 & 0.72 & +0.023 & $+3 \%$ & 0.035 & $5 \%$ & 0.69 \\
Payerne & 136879 & 0.73 & +0.024 & $+3 \%$ & 0.037 & $5 \%$ & 0.60 \\
Xianghe & 33795 & 0.75 & -0.009 & $-1 \%$ & 0.036 & $5 \%$ & 0.37 \\
Tateno & 133433 & 0.72 & +0.019 & $+3 \%$ & 0.039 & $5 \%$ & 0.45 \\
Sede Boqer & 304550 & 0.75 & +0.010 & $+1 \%$ & 0.032 & $4 \%$ & 0.55 \\
Tamanrasset & 331045 & 0.79 & +0.013 & $+2 \%$ & 0.027 & $4 \%$ & 0.71 \\
Brasilia & 73563 & 0.74 & +0.022 & $+3 \%$ & 0.032 & $4 \%$ & 0.74 \\
Alice Springs & 442315 & 0.77 & +0.013 & $+2 \%$ & 0.024 & $3 \%$ & 0.83 \\
Lauder & 117090 & 0.74 & +0.015 & $+2 \%$ & 0.029 & $4 \%$ & 0.75 \\
\hline
\end{tabular}

Table 5. Comparison between clear-sky beam clearness indices on horizontal surface measured by BSRN and estimated by McClear.

\begin{tabular}{llrrrrrr}
\hline Station & $\begin{array}{l}\text { Number of } \\
\text { samples }\end{array}$ & $\begin{array}{r}\text { Mean } \\
\text { observed } \\
\text { value }\end{array}$ & Bias & $\begin{array}{r}\text { Rel. } \\
\text { bias } \\
\%\end{array}$ & RMSE & $\begin{array}{r}\text { Rel. } \\
\text { RMSE } \\
\%\end{array}$ & $\begin{array}{r}\text { Squared } \\
\text { correl. } \\
\text { coeff. }\end{array}$ \\
\hline Barrow & 70283 & 0.61 & -0.040 & $-6 \%$ & 0.066 & $11 \%$ & 0.55 \\
Palaiseau & 29222 & 0.58 & -0.011 & $-2 \%$ & 0.046 & $8 \%$ & 0.61 \\
Carpentras & 300468 & 0.60 & -0.004 & $-1 \%$ & 0.044 & $7 \%$ & 0.64 \\
Payerne & 136879 & 0.61 & +0.004 & $1 \%$ & 0.048 & $8 \%$ & 0.53 \\
Xianghe & 33795 & 0.61 & -0.025 & $-4 \%$ & 0.069 & $11 \%$ & 0.24 \\
Tateno & 133433 & 0.59 & -0.021 & $-4 \%$ & 0.057 & $10 \%$ & 0.44 \\
Sede Boqer & 304550 & 0.64 & -0.053 & $-8 \%$ & 0.067 & $11 \%$ & 0.59 \\
Tamanrasset & 331045 & 0.66 & +0.014 & $+2 \%$ & 0.043 & $7 \%$ & 0.64 \\
Brasilia & 73563 & 0.63 & +0.029 & $+5 \%$ & 0.044 & $7 \%$ & 0.75 \\
Alice Springs & 442315 & 0.67 & +0.002 & $+0 \%$ & 0.037 & $6 \%$ & 0.75 \\
Lauder & 117090 & 0.66 & -0.035 & $-5 \%$ & 0.054 & $8 \%$ & 0.72 \\
\hline
\end{tabular}

Europe (Palaiseau, Carpentras, Payerne) and Australia (Alice Springs), while largest values are found in Xianghe (China, $-22 \mathrm{~W} \mathrm{~m}^{-2}$ ), Sede Boquer (Israel, $-48 \mathrm{~W} \mathrm{~m}^{-2}$ ), Brasilia $\left(+33 \mathrm{~W} \mathrm{~m}^{-2}\right)$, and Lauder (New Zealand, $\left.-32 \mathrm{~W} \mathrm{~m}^{-2}\right)$. The fitting line is close to the identity line, with slopes ranging between 0.96 and 1.04, except for Xianghe (0.86) and Lauder (0.93). The RMSE is small in all cases and ranges between 33 and $68 \mathrm{~W} \mathrm{~m}^{-2}$, i.e. less than $5 \%$ to $11 \%$ of the observed means. Largest RMSEs $\left(\geq 50 \mathrm{~W} \mathrm{~m}^{-2}\right)$ are found for stations offering large bias (Xianghe and Sede Boqer). The good performances in $E^{\text {dir }}$ are likely due to the accurate representation of aerosol properties and their change in time by the MACC data.

As a whole, we have observed no clear trend in performances with year, or aerosol properties and type, ground albedo, or content in ozone and water vapour. Similarly to $E^{\text {glo }}$, the statistical quantities vary slightly from one year to another. Results are usually better for the winter months than for summer, contrary to $E^{\text {glo }}$. The bias varies with $\Theta_{\mathrm{S}}$ though no trend appears (Fig. 14). Except for Xianghe and Sede
Boqer, the RMSE decreases with increasing $\Theta_{\mathrm{S}}$ (Fig. 15). The relative bias and the relative RMSE are not constant as a function of $\Theta_{\mathrm{S}}$.

The circumsolar irradiance was not taken into account to adjust $E^{\text {dir }}$ estimated by McClear to ground measurements. Pyrheliometers have an aperture angle of $5^{\circ}$, and therefore include part of the circumsolar radiation into the measured $E^{\mathrm{dir}}$. This circumsolar irradiance under clear sky is less than $10 \mathrm{~W} \mathrm{~m}^{-2}$ (Oumbe et al., 2012); it may partly explain the bias in case of underestimation.

The diffuse component $E^{\text {diff }}$ is computed by subtracting $E^{\text {dir }}$ from $E^{\text {glo }}$. Therefore, the bias in $E^{\text {diff }}$ can be computed from Tables 2 and 3 . It ranges from -8 to $60 \mathrm{~W} \mathrm{~m}^{-2}$. As a whole, $E^{\text {diff }}$ is overestimated, except for Brasilia and Tamanrasset.

The bias for the clearness index KT (Table 4) ranges from $-0.017(-2 \%)$ to $0.022(3 \%)$. The relative RMSE comprises between $4 \%$ and $5 \%$ of the mean observed value. The squared correlation coefficients for the clearness index KT have been reported in Table 4 . They should be discussed 


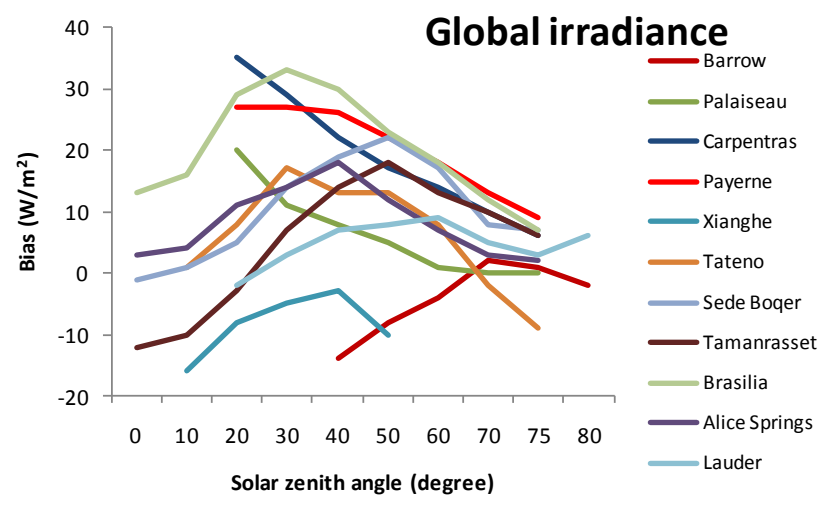

Fig. 12. Change in bias as a function of the solar zenith angle for all stations. Global irradiance.

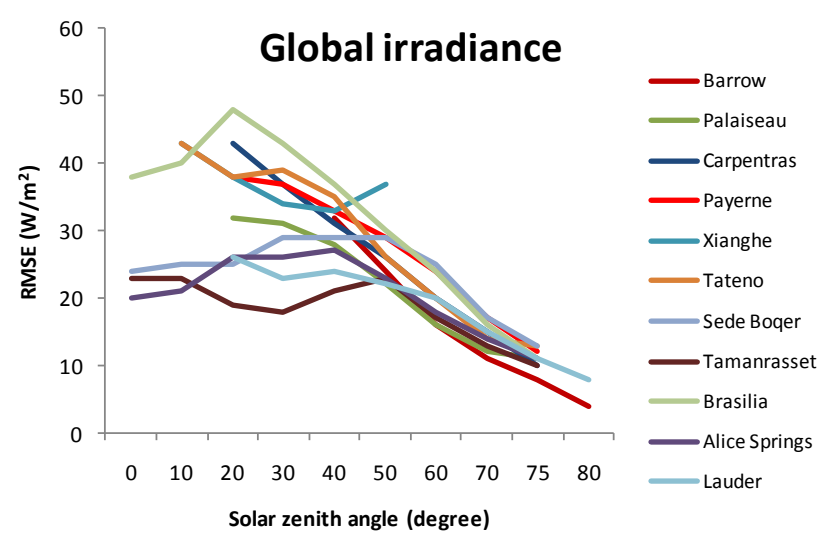

Fig. 13. Change in RMSE as a function of the solar zenith angle for all stations. Global irradiance.

with care as the limited range of values tends to decrease the correlation coefficient without denoting poor performance as discussed previously.

The bias for $\mathrm{KT}^{\mathrm{dir}}$ (Table 5) ranges from -0.053 (Sede Boquer, $-8 \%$ ) to 0.029 (Brasilia, $+5 \%$ ). The relative RMSE comprises between $6 \%$ and $11 \%$ of the mean observed value.

One may note that the stations Carpentras, Payerne, Xianghe, Tateno, and Lauder have elevations below the mean MACC elevation (Table 1). No further elevation correction is applied in these cases; the elevation used for computation is the mean MACC elevation. Consequently, one may expect an overestimation of the direct component because of the theoretical underestimation of the air mass. This is not what is observed; over these 5 cases, 4 exhibit underestimation. For the time being, this effect is unnoticeable compared to remaining uncertainties in aerosol modelling as input data source.

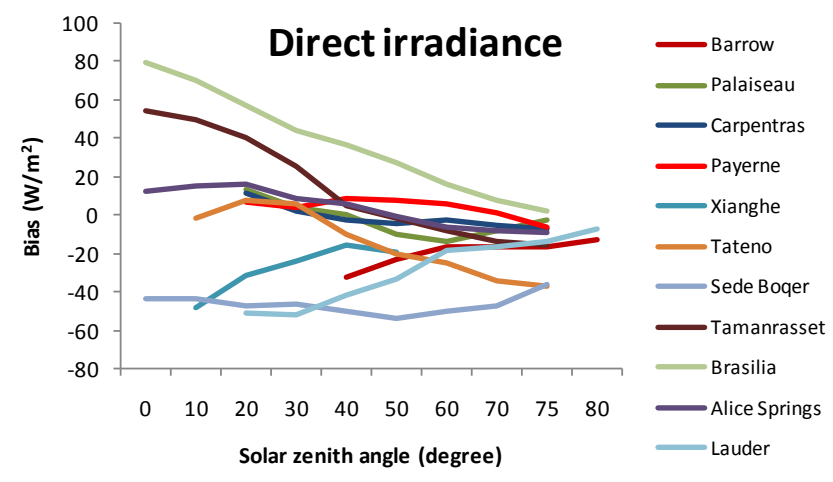

Fig. 14. Change in bias as a function of the solar zenith angle for all stations. Direct irradiance.

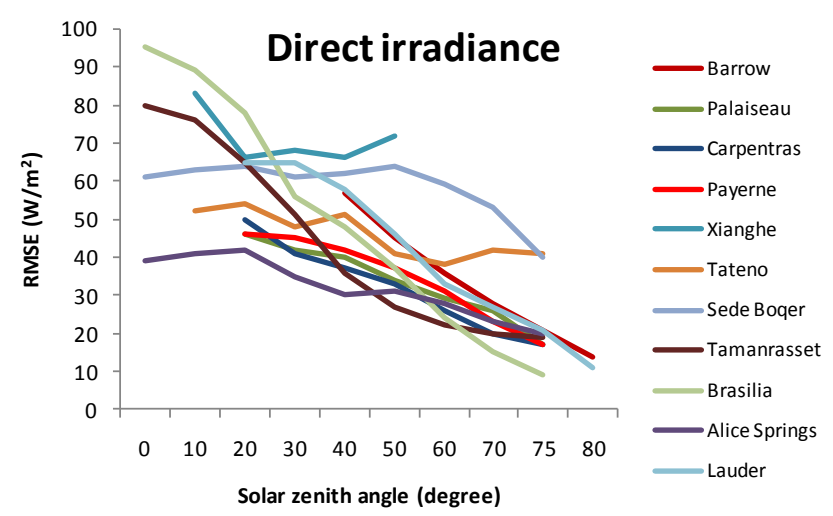

Fig. 15. Change in RMSE as a function of the solar zenith angle for all stations. Direct irradiance.

\section{Comparison with other modelled clear-sky values}

Several models for assessing the SSI under clear sky can be found in the literature. They are usually validated against ground measurements as done in the present work but with a noticeable difference: inputs are atmospheric parameters taken from collocated measuring instruments. Hence these validations qualify the intrinsic performances of the model rather than its real-life performances (Gueymard, 2012; Ineichen, 2006; Mueller et al., 2004; Rigollier et al., 2000).

Schillings et al. (2004) have performed validation of their model against hourly irradiance received on a plane normal to the sun rays for 8 sites in Saudi Arabia. Clear-sky instants are defined by the values of their model. Their results cannot be directly compared to ours which have been obtained for $E^{\mathrm{dir}}$ (horizontal surface). However, relative RMSE can be compared: it ranges from $13 \%$ to $17 \%$ in their case, and $7 \%$ (Tamanrasset) and 9\% (Sede Boqer) in ours.

Greuell et al. (2013) have developed a method for the retrieval of hourly means of the SSI using Meteosat images. MACC data are inputs to their method. Comparisons were made with several BSRN stations for the year 2006 for clearsky cases and all skies. Though the period is not similar and 
Table 6. Comparison between clear-sky global irradiances on a horizontal surface measured by BSRN and estimated by HelioClim-3v3 (HC3v3, in italics) or by McClear.

\begin{tabular}{|c|c|c|c|c|c|c|c|c|}
\hline Station & & $\begin{array}{l}\text { Number of } \\
\text { samples }\end{array}$ & $\begin{array}{r}\text { Mean } \\
\text { observed } \\
\text { value } \mathrm{W} \mathrm{m}^{-2}\end{array}$ & $\begin{array}{r}\text { Bias } \\
\mathrm{W} \mathrm{m}^{-2}\end{array}$ & $\begin{array}{r}\text { Rel. } \\
\text { bias } \\
\%\end{array}$ & $\begin{array}{l}\text { RMSE } \\
\mathrm{W} \mathrm{m}^{-2}\end{array}$ & $\begin{array}{r}\text { Rel. } \\
\text { RMSE } \\
\%\end{array}$ & $\begin{array}{r}\text { Squared } \\
\text { correl. } \\
\text { coeff. }\end{array}$ \\
\hline \multirow[t]{2}{*}{ Palaiseau } & $H C 3 v 3$ & 28292 & 598 & -1 & $-0 \%$ & 62 & $10 \%$ & 0.97 \\
\hline & McClear & 29222 & 598 & +7 & $+1 \%$ & 25 & $4 \%$ & 0.99 \\
\hline \multirow{2}{*}{ Carpentras } & $H C 3 v 3$ & 298410 & 596 & -11 & $-2 \%$ & 45 & $8 \%$ & 0.98 \\
\hline & McClear & 300468 & 596 & +20 & $+3 \%$ & 29 & $5 \%$ & 0.99 \\
\hline \multirow[t]{2}{*}{ Payerne } & $H C 3 v 3$ & 136225 & 629 & -43 & $-7 \%$ & 62 & $10 \%$ & 0.96 \\
\hline & McClear & 136879 & 629 & +23 & $+4 \%$ & 31 & $5 \%$ & 0.99 \\
\hline \multirow[t]{2}{*}{ Sede Boqer } & $H C 3 v 3$ & 303869 & 784 & -35 & $-4 \%$ & 54 & $7 \%$ & 0.96 \\
\hline & McClear & 304550 & 785 & +12 & $+2 \%$ & 27 & $4 \%$ & 0.99 \\
\hline \multirow[t]{2}{*}{ Tamanrasset } & $H C 3 v 3$ & 330194 & 791 & -24 & $-3 \%$ & 37 & $5 \%$ & 0.99 \\
\hline & McClear & 331045 & 791 & +8 & $+1 \%$ & 20 & $3 \%$ & 0.99 \\
\hline
\end{tabular}

Table 7. Comparison between clear-sky beam irradiances on a horizontal surface measured by BSRN and estimated by HelioClim-3v3 (HC3v3, in italics) or by McClear.

\begin{tabular}{|c|c|c|c|c|c|c|c|c|}
\hline Station & & $\begin{array}{l}\text { Number of } \\
\text { samples }\end{array}$ & $\begin{array}{r}\text { Mean } \\
\text { observed } \\
\text { value } \mathrm{W} \mathrm{m}^{-2}\end{array}$ & $\begin{array}{r}\text { Bias } \\
\mathrm{W} \mathrm{m}^{-2}\end{array}$ & $\begin{array}{r}\text { Rel. } \\
\text { bias } \\
\%\end{array}$ & $\begin{array}{l}\text { RMSE } \\
\mathrm{W} \mathrm{m}^{-2}\end{array}$ & $\begin{array}{r}\text { Rel. } \\
\text { RMSE } \\
\%\end{array}$ & $\begin{array}{r}\text { Squared } \\
\text { correl. } \\
\text { coeff. }\end{array}$ \\
\hline \multirow[t]{2}{*}{ Palaiseau } & $H C 3 v 3$ & 28292 & 492 & -14 & $-3 \%$ & 79 & $16 \%$ & 0.91 \\
\hline & McClear & 29222 & 492 & -3 & $-1 \%$ & 37 & $7 \%$ & 0.96 \\
\hline \multirow{2}{*}{ Carpentras } & $H C 3 v 3$ & 298410 & 505 & -46 & $-9 \%$ & 76 & $15 \%$ & 0.93 \\
\hline & McClear & 300468 & 505 & -1 & $-0 \%$ & 35 & $7 \%$ & 0.97 \\
\hline \multirow{2}{*}{ Payerne } & $H C 3 v 3$ & 136225 & 530 & -94 & $-18 \%$ & 111 & $21 \%$ & 0.90 \\
\hline & McClear & 136879 & 530 & +6 & $+1 \%$ & 39 & $7 \%$ & 0.96 \\
\hline \multirow[t]{2}{*}{ Sede Boqer } & $H C 3 v 3$ & 303869 & 667 & -89 & $-13 \%$ & 118 & $18 \%$ & 0.85 \\
\hline & McClear & 304550 & 667 & -48 & $-7 \%$ & 62 & $9 \%$ & 0.95 \\
\hline \multirow[t]{2}{*}{ Tamanrasset } & $H C 3 v 3$ & 330194 & 653 & -14 & $-2 \%$ & 87 & $13 \%$ & 0.86 \\
\hline & McClear & 331045 & 653 & +16 & $+2 \%$ & 48 & $7 \%$ & 0.95 \\
\hline
\end{tabular}

comparisons were made on an hourly basis rather than $1 \mathrm{~min}$, performances can be compared for the bias for the three common sites: Palaiseau, Carpentras, and Payerne. Both models provide similar results for both $E^{\mathrm{glo}}$ and $E^{\mathrm{dir}}$.

The SoDa Web site (www.soda-is.org) provides SSI from the database HelioClim-3v3 (HC3v3, Blanc et al., 2010; Espinar et al., 2012). The HelioClim database derives from images of the Meteosat series of satellites using the Heliosat2 method (Rigollier et al., 2004) and the ESRA clear-sky model (Wald et al., 2000; Rigollier et al., 2000) modified by Geiger et al. (2002) with the climatology of the Linke turbidity factor from Remund et al. (2003) as inputs. The Linke turbidity factor is a convenient approximation to model the atmospheric absorption and scattering of the solar radiation under clear sky. The climatology of Remund et al. (2003) comprises 12 maps, one per month, covering the world by cells of $5^{\prime}$ of arc angle in size. The SoDa Service is able to provide $1 \mathrm{~min} E^{\text {glo }}$ which is compared to that from BSRN for the clear-sky instants and the stations in the field-of-view of Meteosat: Palaiseau, Carpentras, Payerne, Sede Boqer, and Tamanrasset.
Tables 6 and 7 report bias, RMSE and squared correlation coefficient for $\mathrm{HC} 3 \mathrm{v} 3$ and $\mathrm{McCl}$ ear respectively. It appears clearly than the performances of McClear are much better than those of $\mathrm{HC} 3 v 3$. Knowing that $\mathrm{HC} 3 \mathrm{v} 3$ is exploited by many companies and researchers in solar energy - approximately 2 million time series of HC3v3 were supplied by the SoDa Service in 2011 - one may measure the strong interest in McClear in this community.

\section{Conclusions}

The new clear-sky model McClear exhibits very satisfactory results as a fast implementation of radiative transfer theory for the direct and global irradiance. The comparison between McClear estimates and measurements of global and beam SSI for 11 stations in the world shows that a large correlation is attained. For $1 \mathrm{~min}$ averages of global irradiance, the correlation coefficient ranges between 0.95 and 0.99 . The bias comprises between -6 and $25 \mathrm{~W} \mathrm{~m}^{-2}$, and the RMSE between $20 \mathrm{~W} \mathrm{~m}^{-2}$ (3\% of the mean observed 
irradiance) and $36 \mathrm{~W} \mathrm{~m}^{-2}(5 \%)$. For direct irradiance, the correlation coefficient ranges between 0.84 and 0.99 . The bias comprises between -48 and $33 \mathrm{~W} \mathrm{~m}^{-2}$, and the RMSE between $33 \mathrm{~W} \mathrm{~m}^{-2}$ ( $5 \%$ of the mean observed irradiance) and $64 \mathrm{~W} \mathrm{~m}^{-2}(10 \%)$. As a whole, $95 \%$ of the deviations are less than approximately $50 \mathrm{~W} \mathrm{~m}^{-2}$ for global and $70 \mathrm{~W} \mathrm{~m}^{-2}$ for direct irradiance.

Comparisons with state-of-the-art clear-sky models show that McClear offers similar or better performances. These very good results demonstrate the quality of the McClear model and indirectly the quality of the aerosol properties modelled by the MACC reanalysis.

Performances are still far from WMO standards: bias less than $3 \mathrm{~W} \mathrm{~m}^{-2}$ and $95 \%$ of the deviations less than $20 \mathrm{~W} \mathrm{~m}^{-2}$. Uncertainties in aerosol properties from MACC are still too large, and more efforts are necessary for a better modelling of the aerosols.

The novelty of the McClear model is the inclusion of variable aerosol optical properties, water vapour, and ozone with a high update frequency of $3 \mathrm{~h}$ compared to the previously used monthly climatologies in clear-sky models. The large correlation coefficient and the low standard deviation, computed from the RMSE and bias, demonstrate that McClear offers accurate estimates of changes in time of the SSI.

Since MACC provides also forecasts of the aerosol properties and ozone, and various meteorological services provide forecasts of water vapour from any NWP centre, McClear can also be used for forecasting of clear-sky irradiances in future.

The McClear model with inputs from MACC and MODIS is available as a Web service, i.e. an application that can be invoked via the Web. It obeys the OGC (Open Geospatial Consortium) standard for Web processing services (WPS) (Percivall et al., 2011). An interface has been developed to launch McClear within a standard Web browser and to obtain time series of global and beam SSI under clear sky for a given point and a given period for the following summarizations: $1 \mathrm{~min}, 15 \mathrm{~min}, 1 \mathrm{~h}$ and 1 day. This interface can be launched via the catalogue of products on the MACC Web site (www.gmes-atmosphere.eu).

Acknowledgements. The research leading to these results has received funding from the European Union's Seventh Framework Programme (FP7/2007-2013) under grant agreement no. 218793 (MACC project) and no. 283576 (MACC-II project). The authors thank all ground station operators of the BSRN network for their valuable measurements and the Alfred Wegener Institute for hosting the BSRN website. The authors thank the team developing libRadtran (http://www.libradtran.org) and Laurent Saboret for his valuable help in setting up the McClear application on the Web. They also thank the anonymous reviewers whose efforts help in bringing clarity in our work.

Edited by: G. de Leeuw

\section{References}

Ba, M., Frouin, R., Nicholson, S., and Dedieu, G.: Satellite-derived surface radiation budget over the African continent. Part I: Estimation of downward solar irradiance and albedo, J. Climate, 14, 60-76, 2001.

Benedetti, A., Morcrette, J.-J., Boucher, O., Dethof, A., Engelen, R. J., Fisher, M., Flentje, H., Huneeus, N., Jones, L., Kaiser, J. W., Kinne, S., Manglold, A., Razinger, M., Simmons, A. J., and Suttie, M.: Aerosol analysis and forecast in the European Centre for Medium-Range Weather Forecasts Integrated Forecast System: 2. Data assimilation, J. Geophys. Res., 114, D13205, doi:10.1029/2008JD011115, 2009.

Blanc, P. and Wald, L.: The SG2 algorithm for a fast and accurate computation of the position of the Sun, Sol. Energy, 86, 30723083, doi:10.1016/j.solener.2012.07.018, 2012.

Blanc, P., Gschwind, B., Lefèvre, M., and Wald, L.: The HelioClim project: Surface solar irradiance data for climate applications, Remote Sens., 3, 343-361, doi:10.3390/rs3020343, 2010.

Cano, D., Monget, J. M., Albuisson, M., Guillard, H., Regas, N., and Wald, L.: A method for the determination of the global solar radiation from meteorological satellites data, Sol. Energy, 37, 31-39, 1986.

Darnell, W. L., Staylor, W. F., Ritchey, N. A., Gupta, S. K., and Wilber, A. C.: Surface radiation budget: A long-term global dataset of shortwave and longwave fluxes, EOS T. Am. Geophys. Un., available at: http://www.agu.org/eos_elec/95206.html (last access: 17 September 2013), 27 February 1996.

Deepshikha, S., Satheesh, S. K., and Srinivasan, J.: Dust aerosols over India and adjacent continents retrieved using METEOSAT infrared radiance Part I: sources and regional distribution, Ann. Geophys., 24, 37-61, doi:10.5194/angeo-24-37-2006, 2006.

Deneke, H. M., Feijt, A. J., and Roebeling, R. A.: Estimating surface solar irradiance from Meteosat SEVIRI-derived cloud properties, Remote Sens. Environ., 12, 3131-3141, 2008.

Diabaté, L., Demarcq, H., Michaud-Regas, N., and Wald, L.: Estimating incident solar radiation at the surface from images of the Earth transmitted by geostationary satellites: the Heliosat Project, Int. J. Solar Energy, 5, 261-278, 1988.

Elias, T. and Roujean, J.-L.: Estimation of the aerosol radiative forcing at ground level, over land, and in cloudless atmosphere, from METEOSAT-7 observation: method and case study, Atmos. Chem. Phys., 8, 625-636, doi:10.5194/acp-8-625-2008, 2008.

Espinar, B., Wald, L., Blanc, P., Lefèvre, M., Gschwind, B., Ménard, L., Wey, E., Thomas, C., and Saboret, L.: HELIOCLIM-3: A near-real time and long-term surface solar irradiance database, Workshop on Remote Sensing Measurements for Renewable Energy, 22-23 May 2012, available at: http://hal-ensmp.archives-ouvertes.fr/docs/00/74/15/64/PDF/ 2012_COST_WIRE_HC3_extended_abstract_v2.pdf (last access: 24 January 2013), Risoe, Denmark, 2012.

FAO: Koeppen climate classification map, available at: www.fao. org/sd/EIdirect/climate/EIsp0002.htm (last access: 21 December 2012), 1997.

GCOS - Global Climate Observing System Essential Climate Variables: available at: www.wmo.int/pages/prog/gcos/index. php?name=EssentialClimateVariables, last access: 16 November 2012.

Geiger, M., Diabaté, L., Ménard, L., and Wald, L.: A web service for controlling the quality of measurements of global solar irra- 
diation, Sol. Energy, 73, 475-480, 2002.

Gruell, W., Meirink, J. F., and Wang, P.: Retrieval and validation of global, direct, and diffuse irradiance derived from SEVIRI satellite observations, J. Geophys. Res. Atmos., 118, 2340-2361, doi:10.1002/jgrd.50194, 2013.

Gueymard, C.: Importance of atmospheric turbidity and associated uncertainties in solar radiation and luminous efficacy modelling, Energy, 30, 1603-1621, 2005.

Gueymard, C.: Clear-sky irradiance predictions for solar resource mapping and large-scale applications: Improved validation methodology and detailed performance analysis of 18 broadband radiative models, Sol. Energy, 86, 2145-2169, doi:10.1016/j.solener.2011.11.011, 2012.

Holzer-Popp, T., Schroedter, M., and Gesell, G.: Retrieving aerosol optical depth and type in the boundary layer over land and ocean from simultaneous GOME spectrometer and ATSR-2 radiometer measurements, 1, Method description, J. Geophys. Res., 107, 4578, doi:10.1029/2001JD002013, 2002.

Huang, G. H., Ma, M. G., Liang, S. L., Liu, S. M., and Li, X.: A LUT-based approach to estimate surface solar irradiance by combining MODIS and MTSAT data, J. Geophys. Res.-Atmos., 116, D22201, doi:10.1029/2011JD016120, 2011.

Ineichen, P.: Comparison of eight clear sky broadband models against 16 independent data banks, Sol. Energy, 80, 468-478, 2006.

Ineichen, P. and Perez, R.: Derivation of cloud index from geostationary satellites and application to the production of solar irradiance and daylight illuminance data, Theor. Appl. Climatol., 64, 119-130, 1999.

Inness, A., Baier, F., Benedetti, A., Bouarar, I., Chabrillat, S., Clark, H., Clerbaux, C., Coheur, P., Engelen, R. J., Errera, Q., Flemming, J., George, M., Granier, C., Hadji-Lazaro, J., Huijnen, V., Hurtmans, D., Jones, L., Kaiser, J. W., Kapsomenakis, J., Lefever, K., Leitão, J., Razinger, M., Richter, A., Schultz, M. G., Simmons, A. J., Suttie, M., Stein, O., Thépaut, J.-N., Thouret, V., Vrekoussis, M., Zerefos, C., and the MACC team: The MACC reanalysis: an $8 \mathrm{yr}$ data set of atmospheric composition, Atmos. Chem. Phys., 13, 4073-4109, doi:10.5194/acp-13-4073-2013, 2013.

ISO Guide to the Expression of Uncertainty in Measurement: first edition, International Organization for Standardization, Geneva, Switzerland, 1995.

Kaiser, J. W., Peuch, V.-H., Benedetti, A., Boucher, O., Engelen, R. J., Holzer-Popp, T., Morcrette, J.-J., Wooster, M. J., and the MACC-II Management Board: The pre-operational GMES Atmospheric Service in MACC-II and its potential usage of Sentinel-3 observations, ESA Special Publication SP708, Proceedings of the 3rd MERIS/(A)ATSR and OCLI-SLSTR (Sentinel-3) Preparatory Workshop, held in ESA-ESRIN, Frascati, Italy, 15-19 October 2012, 2012a.

Kaiser, J. W., Heil, A., Andreae, M. O., Benedetti, A., Chubarova, N., Jones, L., Morcrette, J.-J., Razinger, M., Schultz, M. G., Suttie, M., and van der Werf, G. R.: Biomass burning emissions estimated with a global fire assimilation system based on observed fire radiative power, Biogeosciences, 9, 527-554, doi:10.5194/bg-9-527-2012, 2012 b.

Kasten, F. and Young, A. T.: Revised optical air mass tables and approximation formula, Appl. Optics, 28, 4735-4738, 1989.
Lefèvre, M., Diabaté, L., and Wald, L.: Using reduced data sets ISCCP-B2 from the Meteosat satellites to assess surface solar irradiance, Sol. Energy, 81, 240-253, 2007.

Long, C. N. and Ackerman, T. P.: Identification of clear skies from broadband pyranometer measurements and calculation of downwelling shortwave cloud effects, J. Geophys. Res., 105, 15609, doi:10.1029/2000JD900077, 2000.

Mayer, B. and Kylling, A.: Technical note: The libRadtran software package for radiative transfer calculations - description and examples of use, Atmos. Chem. Phys., 5, 1855-1877, doi:10.5194/acp-5-1855-2005, 2005.

Mayer, B., Kylling, A., Emde, C., Buras, R., and Hamann, U.: libRadtran: library for radiative transfer calculations, Edition 1.0 for libRadtran version 1.5-beta, http://www.libradtran.org (last access: 10 April 2013), 2010.

Morcrette, J.-J., Beljaars, A., Benedetti, A., Jones, L., and Boucher, O.: Sea-salt and dust aerosols in the ecmwf ifs model, Geophys. Res. Lett., 35, L24813, doi:10.1029/2008GL036041, 2008.

Morcrette, J.-J., Boucher, O., Jones, L., Salmond, D., Bechtold, P., Beljaars, A., Benedetti, A., Bonet, A., Kaiser, J. W., Razinger, M., Schulz, M., Serrar, S., Simmons, A. J., Sofiev, M., Suttie, M., Tompkins, A. M., and Untch, A.: Aerosol analysis and forecast in the European Centre for Medium-Range Weather Forecasts Integrated Forecast System: Forward modelling, J. Geophys. Res., 114, D06206, doi:10.1029/2008JD011235, 2009.

Mueller, R., Dagestad, K. F., Ineichen, P., Schroedter, M., Cros, S., Dumortier, D., Kuhlemann, R., Olseth, J. A., Piernavieja, G., Reise, C., Wald, L., and Heinnemann, D.: Rethinking satellite based solar irradiance modelling - The SOLIS clear sky module, Remote Sens. Environ., 91, 160-174, 2004.

Mueller, R., Matsoukas, C., Gratzki, A., Behr, H., and Hollmann, R.: The CM-SAF operational scheme for the satellite based retrieval of solar surface irradiance - a LUT based eigenvector hybrid approach, Remote Sens. Environ., 113, 1012-1024, doi:10.1016/j.rse.2009.01.012, 2009.

Ohmura, A., Gilgen, H., Hegner, H., Mueller, G., Wild, M., Dutton, E. G., Forgan, B., Froelich, C., Philipona, R., Heimo, A., Koenig-Langlo, G., McArthur, B., Pinker, R., Whitlock, C. H., and Dehne, K.: Baseline Surface Radiation Network (BSRN/WCRP): New precision radiometry for climate research, B. Am. Meteorol. Soc., 79, 2115-2136, doi:10.1175/15200477(1998)079<2115:BSRNBW>2.0.CO;2, 1998.

Oumbe, A., Blanc, P., Gschwind, B., Lefevre, M., Qu, Z., Schroedter-Homscheidt, M., and Wald, L.: Solar irradiance in clear atmosphere: study of parameterisations of change with altitude, Adv. Sci. Res., 6, 199-203, doi:10.5194/asr-6-199-2011, 2011.

Oumbe, A., Qu, Z., Blanc, P., Bru, H., Lefèvre, M., and Wald, L.: Modeling circumsolar irradiance to adjust beam irradiances from radiative transfer models to measurements, EMS Annual Meeting 2012, 10-14 September 2012, Lodz, Poland, 2012.

Percivall, G., Ménard, L., Chung, L.-K., Nativi, S., and Pearlman, J.: Geo-processing in cyberinfrastructure: making the web an easy to use geospatial computational platform, in: Proceedings, 34th International Symposium on Remote Sensing of Environment, 10-15 April 2011, available at: www.isprs.org/ proceedings/2011/ISRSE-34/211104015Final00671.pdf (last access: 29 December 2012), Sydney, Australia, 2011. 
Perez, R., Seals, R., and Zelenka, A.: Comparing satellite remote sensing and ground network measurements for the production of site/time specific irradiance data, Sol. Energy, 60, 89-96, 1997.

Peuch, V.-H., Rouil, L., Tarrason, L., and Elbern, H.: Towards European-scale Air Quality operational services for GMES Atmosphere, 9th EMS Annual Meeting, EMS2009-511, 9th European Conference on Applications of Meteorology (ECAM) Abstracts, held 28 September-2 October 2009, Toulouse, France, 2009.

Posselt, R., Mueller, R. W., Stöckli, R., and Trentmann, J.: Remote sensing of solar surface radiation for climate monitoring the CM-SAF retrieval in international comparison, Remote Sens. Environ., 118, 186-198, 2012.

Qu, Z., Blanc, P., Lefèvre, M., Wald, L., and Oumbe, A.: Study of the MLB parameterisation for change in surface solar irradiance with sun zenith angle in clear sky, Adv. Sci. Res., 6, 233-236, doi:10.5194/asr-6-233-2011, 2011.

Raschke, E., Gratzki, A., and Rieland, M.: Estimates of global radiation at the ground from the reduced data sets of the International Satellite Cloud Climatology Project, J. Climate, 7, 205213, 1987.

Remund, J., Wald, L., Lefèvre, M., Ranchin, T., and Page, J.: Worldwide Linke turbidity information, CD-ROM published by International Solar Energy Society, Proceedings of ISES Solar World Congress, 16-19 June, Göteborg, Sweden, 2003.

Rigollier, C., Bauer, O., and Wald, L.: On the clear sky model of the 4th European Solar Radiation Atlas with respect to the Heliosat method, Sol. Energy, 68, 33-48, 2000.

Rigollier, C., Lefèvre, M., and Wald, L.: The method Heliosat-2 for deriving shortwave solar radiation from satellite images, Sol. Energy, 77, 159-169, 2004.

Roesch, A., Wild, M., Ohmura, A., Dutton, E. G., Long, C. N., and Zhang, T.: Assessment of BSRN radiation records for the computation of monthly means, Atmos. Meas. Tech., 4, 339-354, doi:10.5194/amt-4-339-2011, 2011.

Schaepman-Strub, G., Schaepman, M. E., Painter, T. H., Dangel, S., and Martonchik, J. V.: Reflectance quantities in optical remote sensing: Definitions and case studies, Remote Sens. Environ., 103, 27-42, doi:10.1016/j.rse.2006.03.002, 2006.

Schaaf, C. B., Gao, F., Strahler, A. H., Lucht, W., Li, X. W., Tsang, T., Strugnell, N. C., Zhang, X. Y., Jin, Y. F., Muller, J. P., Lewis, P., Barnsley, M., Hobson, P., Disney, M., Roberts, G., Dunderdale, M., Doll, C., d'Entremont, R. P., Hu, B. X., Liang, S. L., Privette, J. L., and Roy, D.: First operational BRDF, albedo nadir reflectance products from MODIS, Remote Sens. Environ., 83, 135-148, doi:10.1016/S0034-4257(02)00091-3, 2002.

Schiffer, R. and Rossow, W. B.: ISCCP global radiance data set: A new resource for climate research, B. Am. Meteorol. Soc., 66, 1498-1503, 1985.

Schillings, C., Meyer, R., and Mannstein, H.: Validation of a method for deriving high resolution direct normal irradiance from satellite data and application for the Arabian Peninsula, Sol. Energy, 76, 485-497, 2004.
Schmetz, J.: Towards a surface radiation climatology: retrieval of downward irradiances from satellites, Atmos. Res., 23, 287-321, 1989.

Schulz, J., Albert, P., Behr, H.-D., Caprion, D., Deneke, H., Dewitte, S., Dürr, B., Fuchs, P., Gratzki, A., Hechler, P., Hollmann, R., Johnston, S., Karlsson, K.-G., Manninen, T., Müller, R., Reuter, M., Riihelä, A., Roebeling, R., Selbach, N., Tetzlaff, A., Thomas, W., Werscheck, M., Wolters, E., and Zelenka, A.: Operational climate monitoring from space: the EUMETSAT Satellite Application Facility on Climate Monitoring (CM-SAF), Atmos. Chem. Phys., 9, 1687-1709, doi:10.5194/acp-9-1687-2009, 2009.

Trewartha, G. T.: An Introduction to Climate, 3rd Edn., McGraw Hill Book Co., 1954.

Vermote, E. F., Tanré, D., Deuzé, J. L., Herman, M., and Morcrette, J. J.: Second Simulation of the satellite signal in the solar spectrum (6S), 6S User Guide, NASA-Goddard Space Flight CenterCode 923, Greenbelt, USA, 1994.

Vermote, E. F., Tanré, D., Deuzé, J. L., Herman, M., and Morcrette, J. J.: Second simulation of the satellite signal in the solar spectrum: An overview, IEEE T. Geosci. Remote, 35, 675-686, 1997.

Wald, L. and Monget, J. M.: Remote sensing of the sea-state using the 0.8-1.1 microns channel (Comments by P. Koepke and reply, 6, 787-799, 1985), Int. J. Remote Sens., 4, 433-446, 1983.

Wald, L., Albuisson, M., Czeplak, G., Bourges, B., Aguiar, R., Lund, H., Joukoff, A., Terzenbach, U., Beyer, H. G., and Borisenko, E. P.: ESRA - European Solar Radiation Atlas, 4th Edn., includ. CD-ROM, edited by: Scharmer, K. and Greif, J., Scientific advisors: Dogniaux, R. and Page, J. K., published for the Commission of the European Communities by Presses de l'Ecole, Ecole des Mines de Paris, Paris, France, 2000.

Wang, Y., Zhao, F., and Li, Z.: Comparison of aerosol radiative forcing observed by AERONET and MODIS at Xianghe Station - Comparison of the aerosol product and its radiative forcing between AERONET and MODIS, PIERS Proceedings, held in Suzhou, China, 12-16 September 2011, available at: http: //piers.org/piersproceedings/piers2011SuzhouProc.php (last access: 24 July 2013), 2011.

WMO: Guide to meteorological instruments and methods of observation, World Meteorological Organization, WMO-No 8, 7th Edn., Geneva, Switzerland, 2008.

Xu, J., Li, C., Shi, H., He, Q., and Pan, L.: Analysis on the impact of aerosol optical depth on surface solar radiation in the Shanghai megacity, China, Atmos. Chem. Phys., 11, 3281-3289, doi:10.5194/acp-11-3281-2011, 2011.

Zelenka, A., Perez, R., Seals, R., and Renné, D.: Effective accuracy of satellite-derived hourly irradiances, Theor. Appl. Climatol., 62, 199-207, 1999. 